\title{
Overview of Illinois Tollway Precast
}

\section{Panel System}

August 11, 2016

Steve Gillen

Deputy Program Manager of Materials

sing omsuma
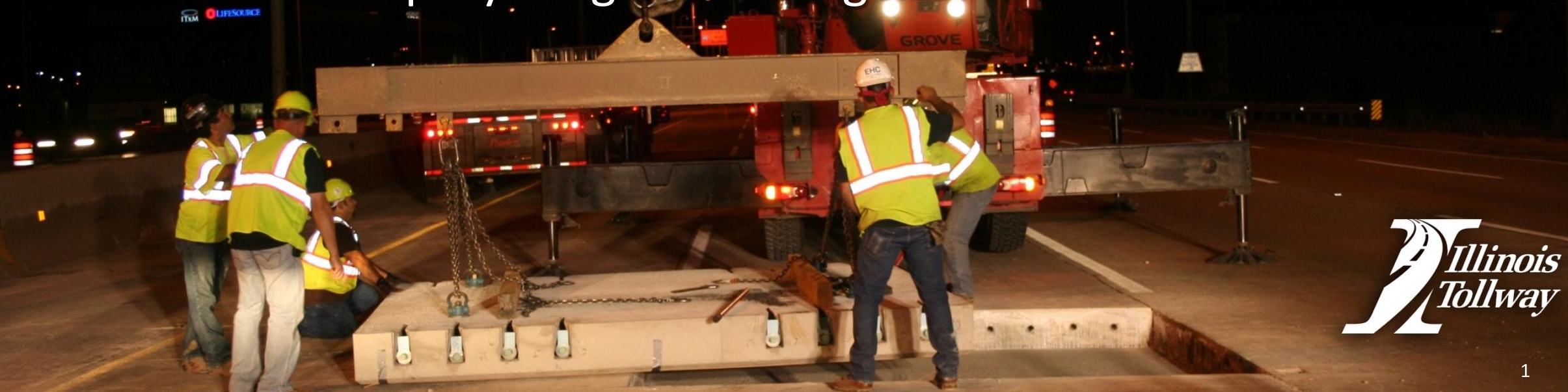


\section{The Move Illinois Program Initiated in 2011}

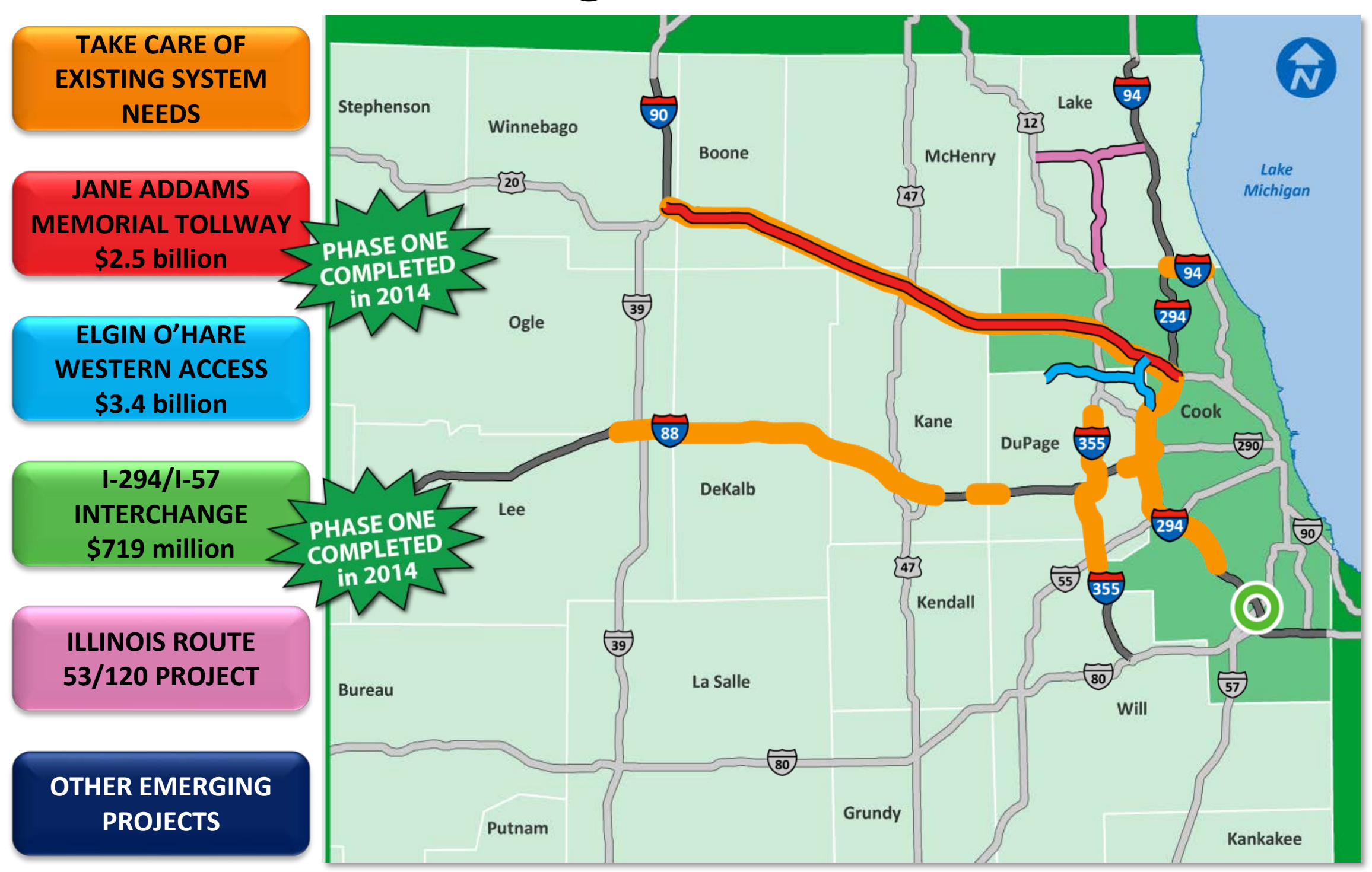




\section{More Sustainable Concrete Pavement Rehabilitation is Needed}

Get In

Get out

$$
\text { \& }
$$

Stay out

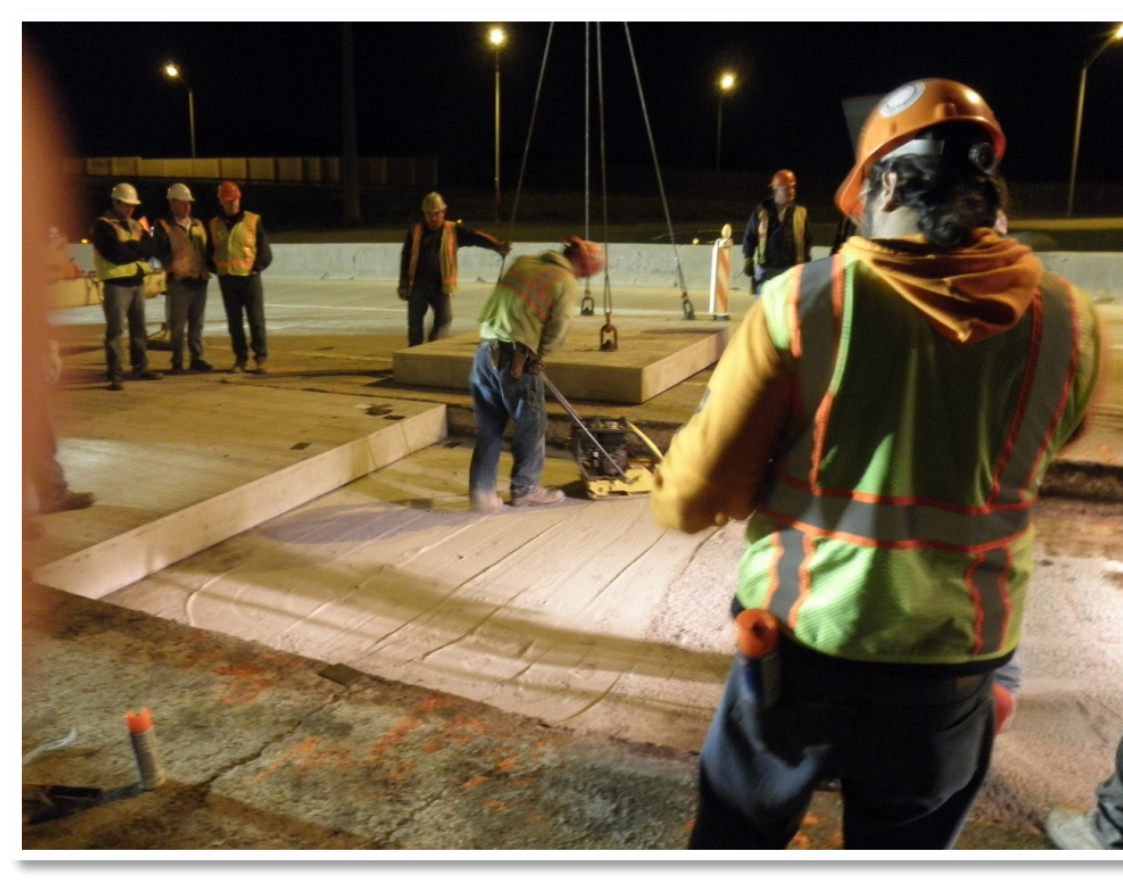


First Precast Application in 2002 - Uretek Method

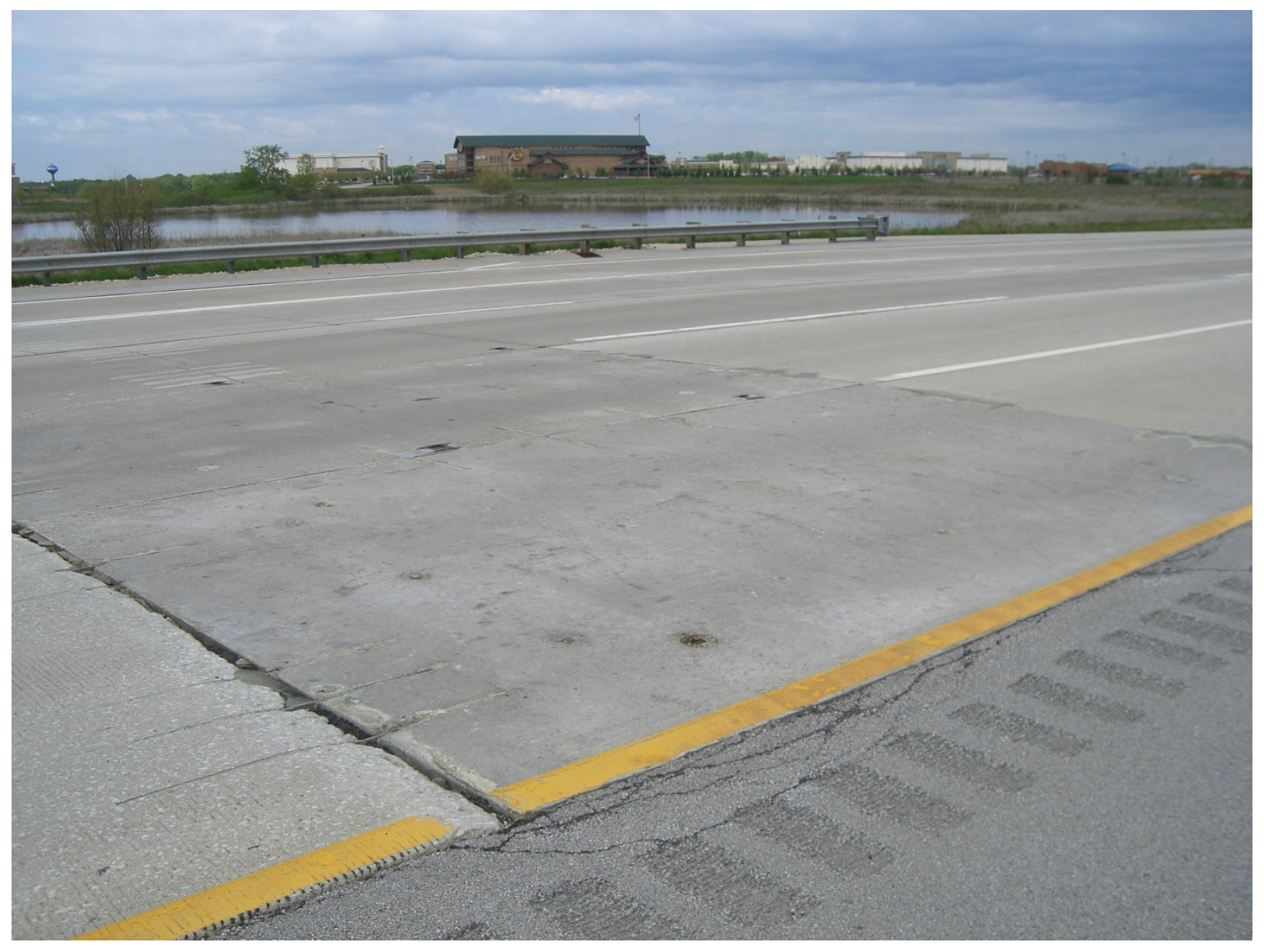




\section{Fort Miller System Introduced in 2007}

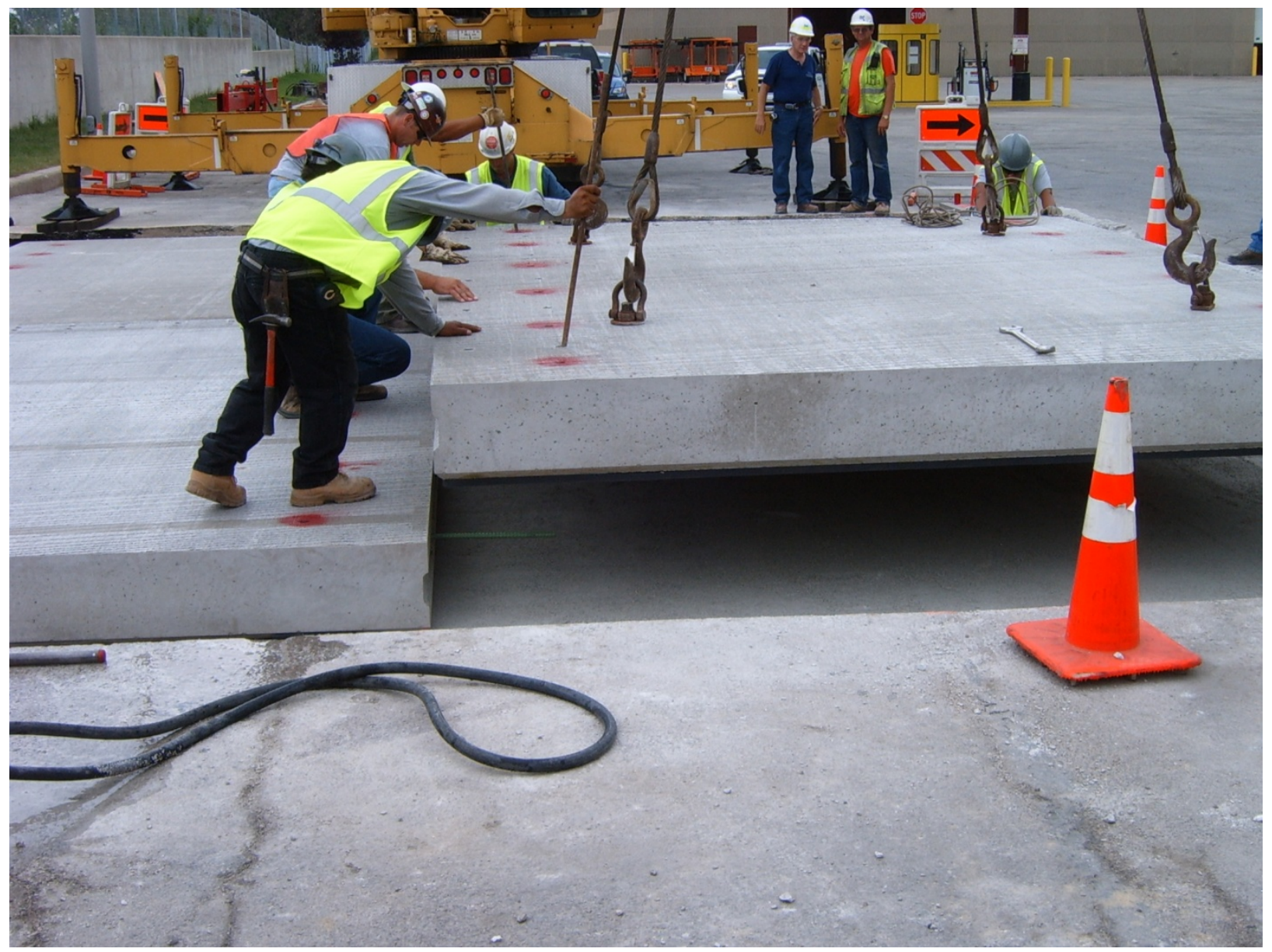


Fort Miller System is Proprietary
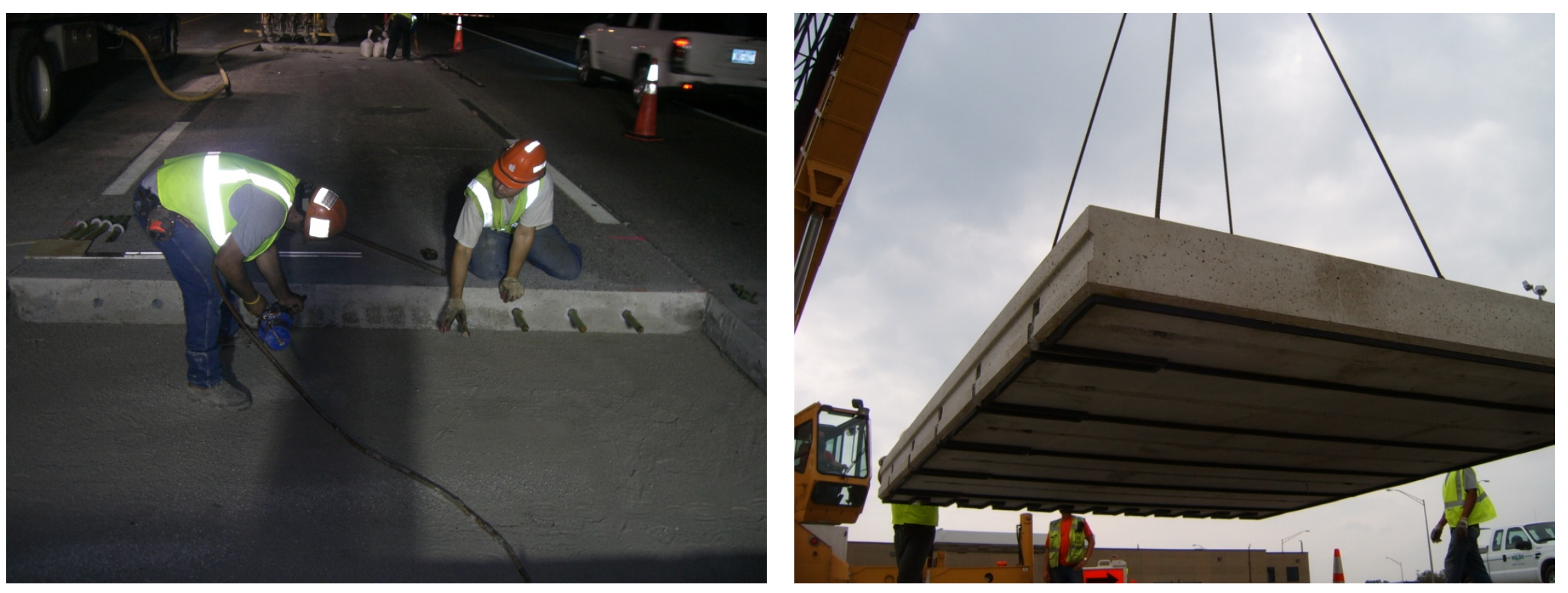


\section{Competition Needed in More Ways than One}

More than 1 precast concrete pavement system was proven to be needed in 2008

To some extent, precast concrete has to compete with high performance cast-in-place concrete 


\section{Tollway's Generic System Developed in 2009}

Refer to: http://www.illinoistollway.com/documents/1015 7/378808/PDF_ISTHA_GBV_SectionA_02072012. pdf
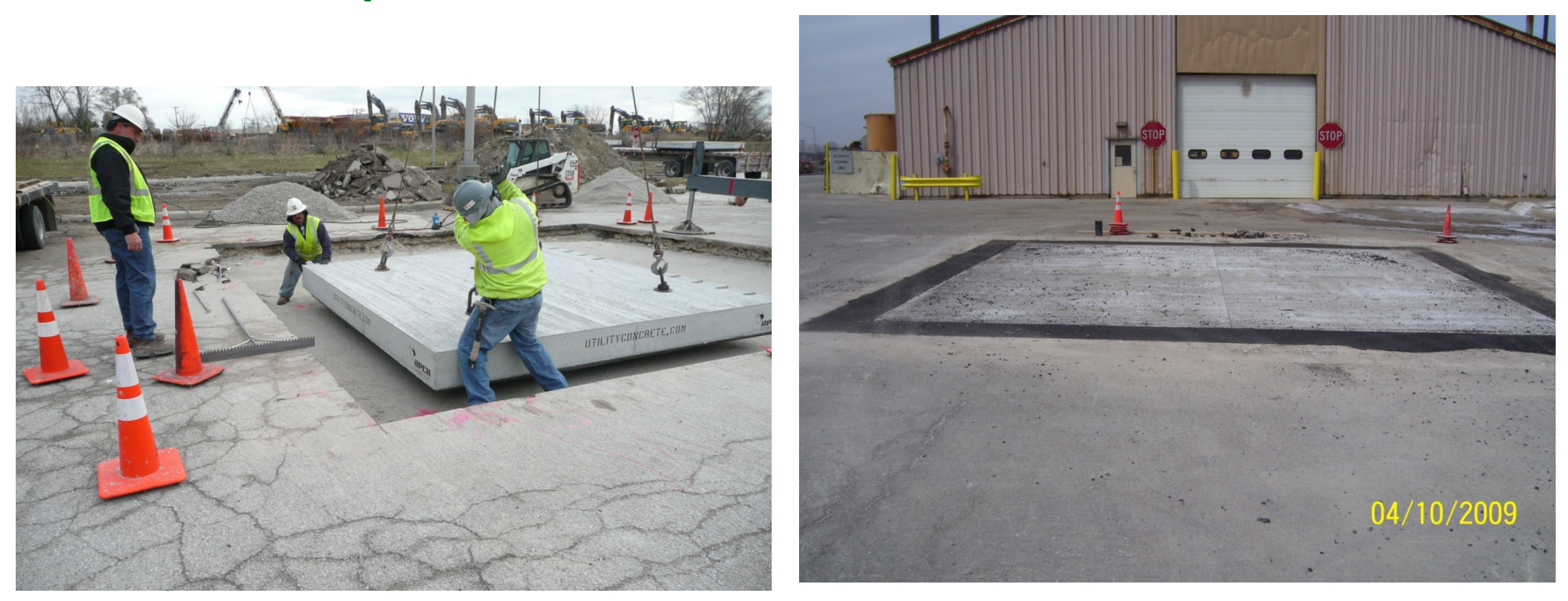


\section{Originally Designed With Sunny Side Up Dowel Bar Connections}

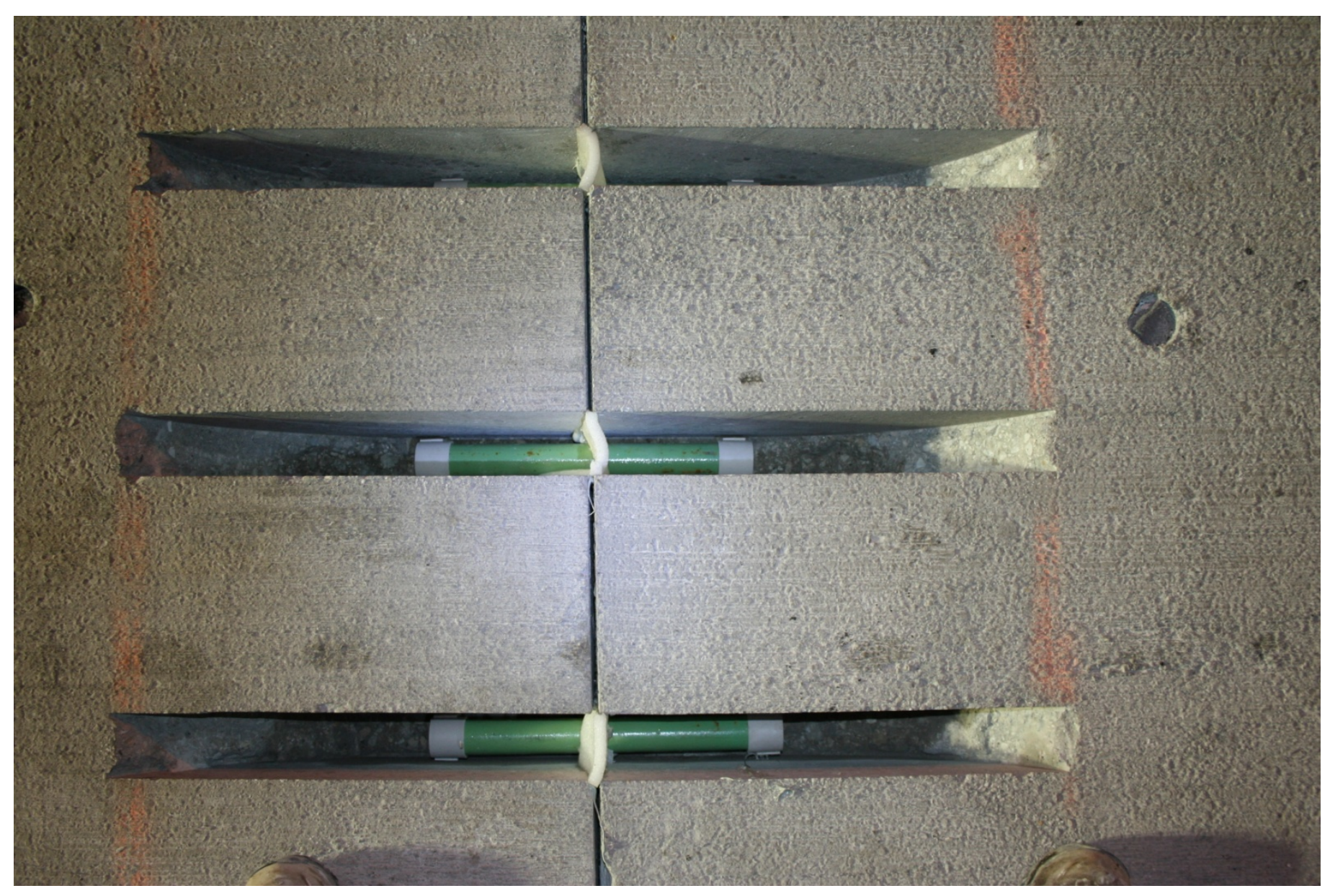




\section{Standard Dowel Bar Retrofit Option}

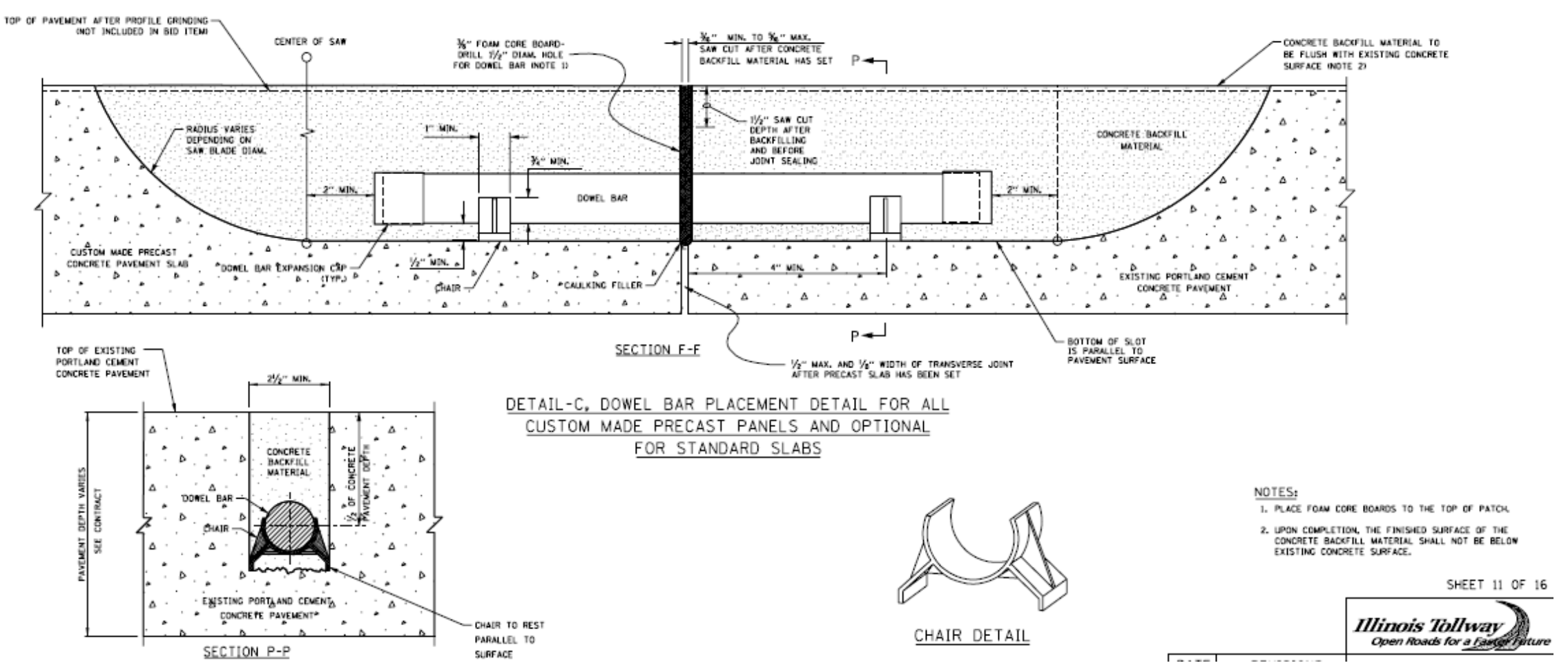




\section{Pre-drill / Narrow Mouth Dowel Connections Now Apply}

Top view

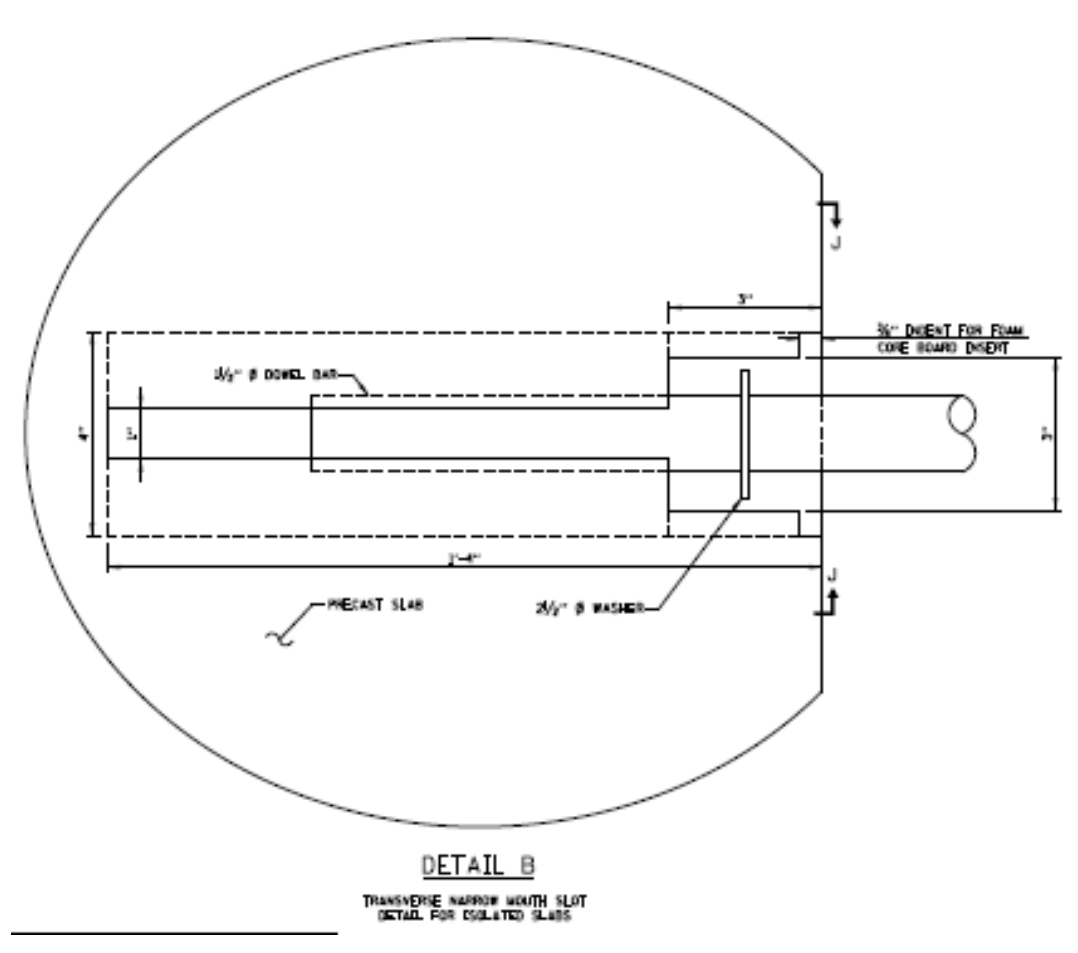

Cross Section

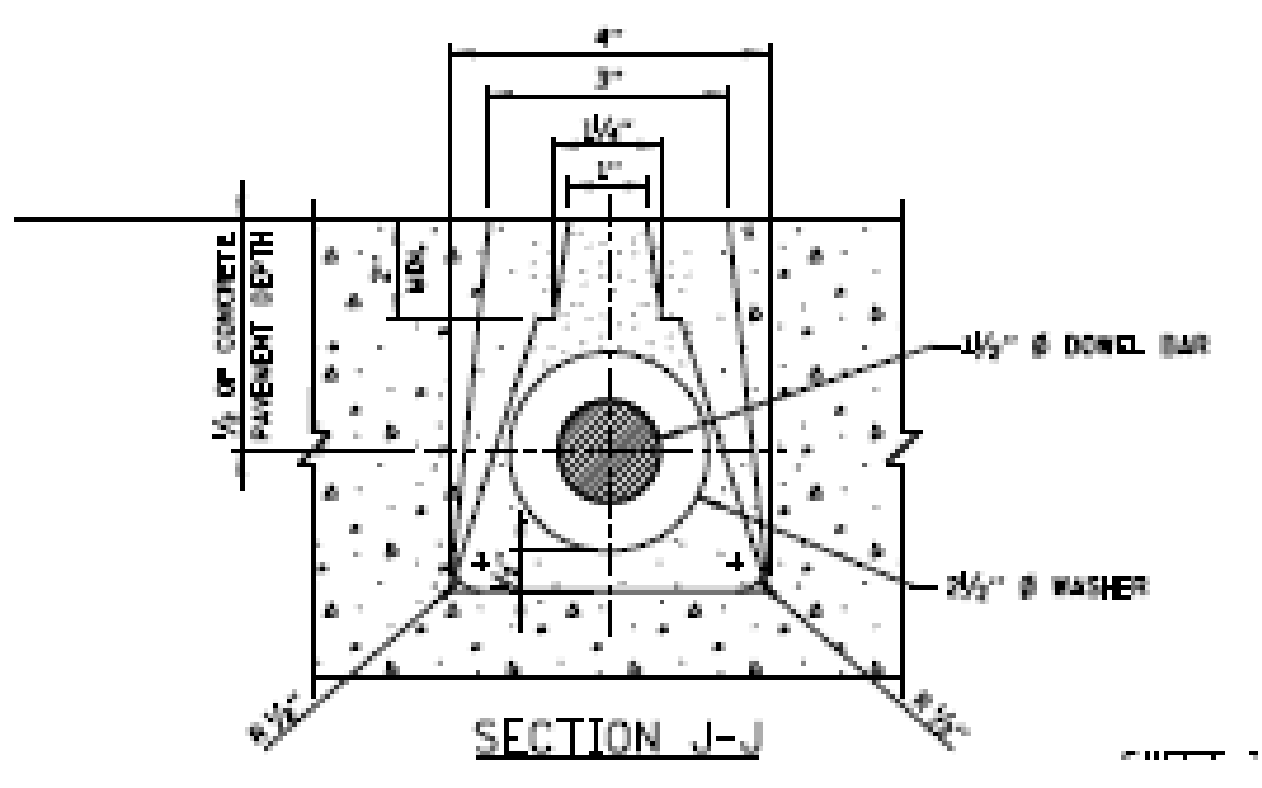




\section{Benefits of Pre Drill / Narrow Mouth Option}
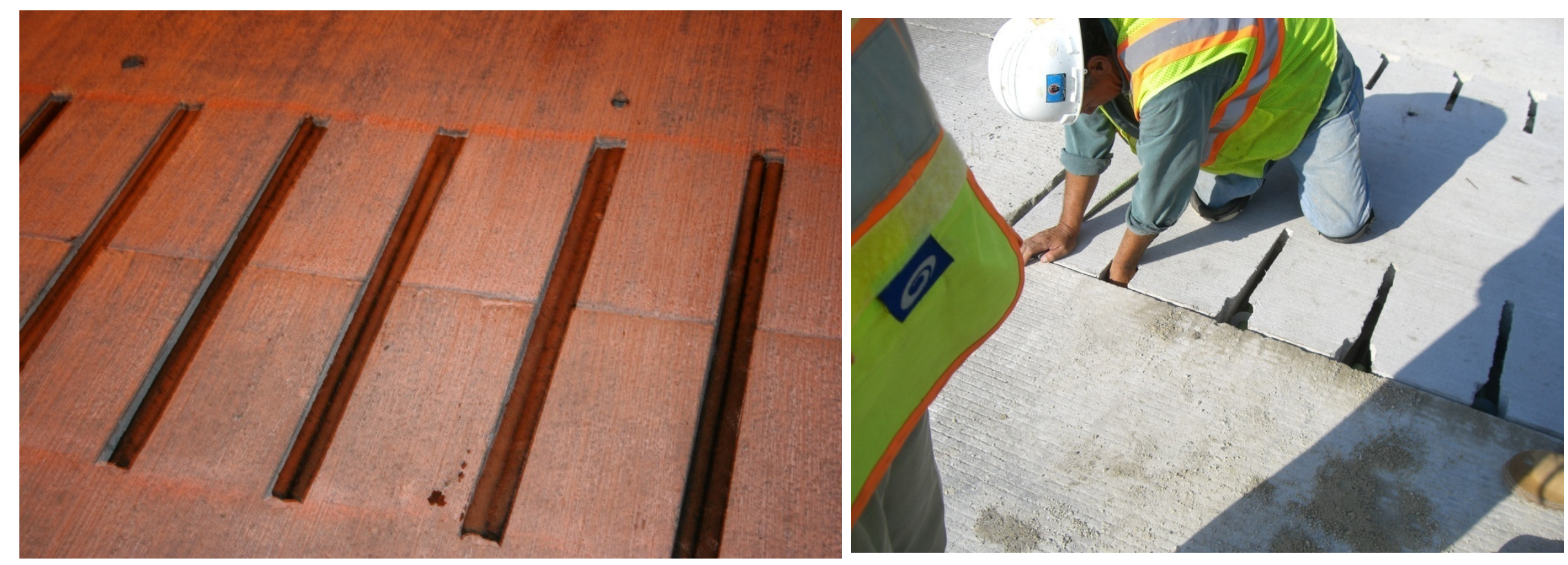


\section{First Step is Survey \& Design}

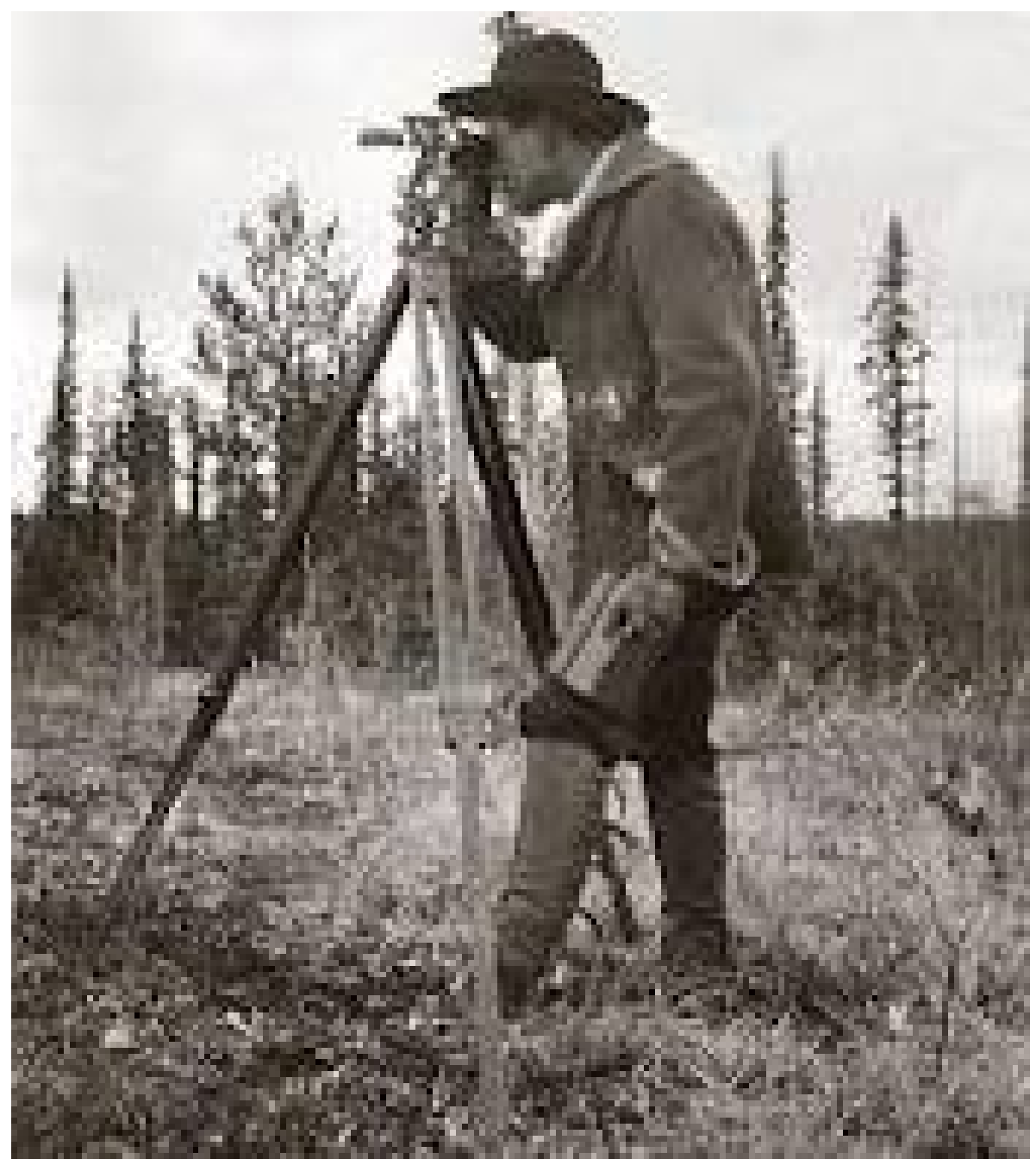




\section{Mark Locations for Saw Cuts}

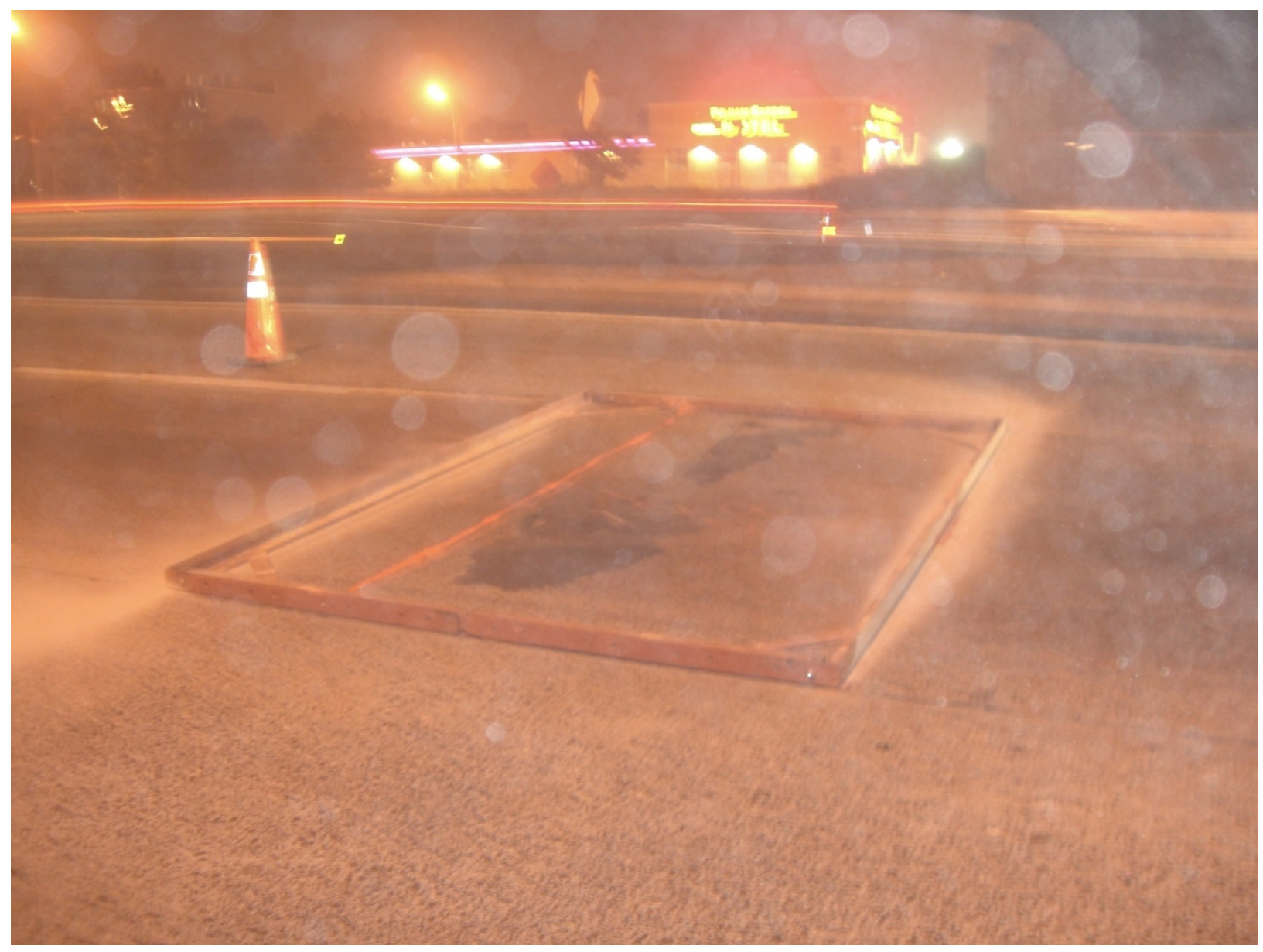




\section{Tollway System Allows for Longitudinal Joint Offsets with Isolated Patching}

Off interior longitudinal joints (3" max.)

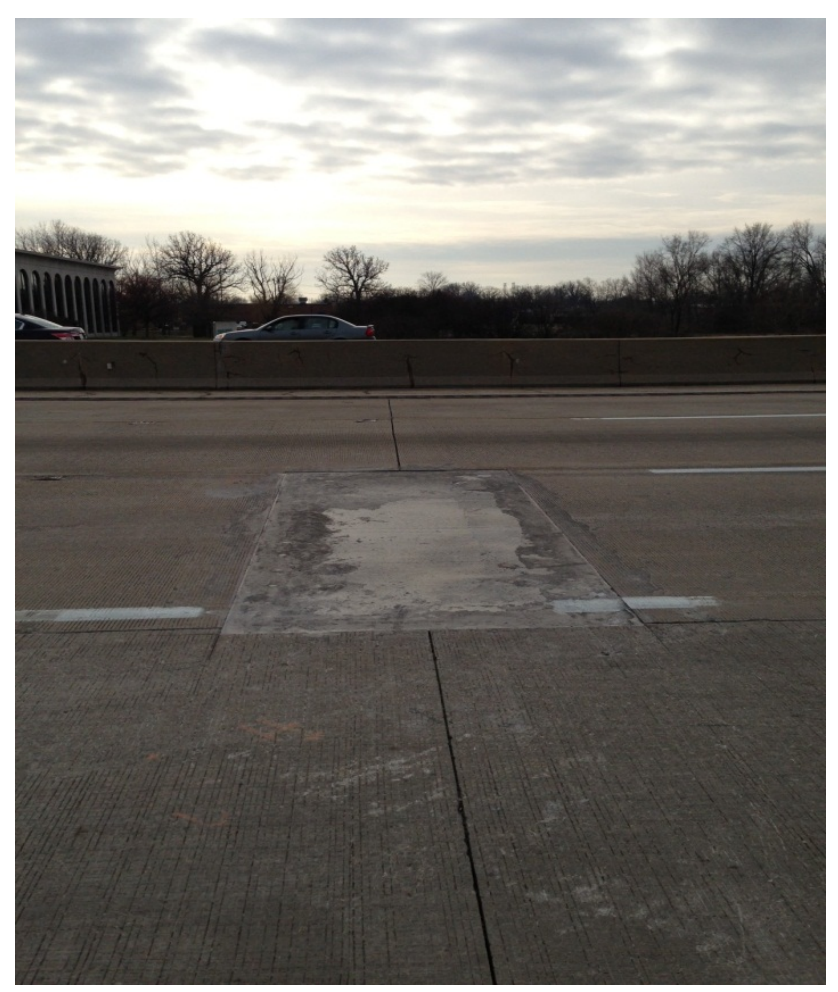

Any distance into asphalt shoulders

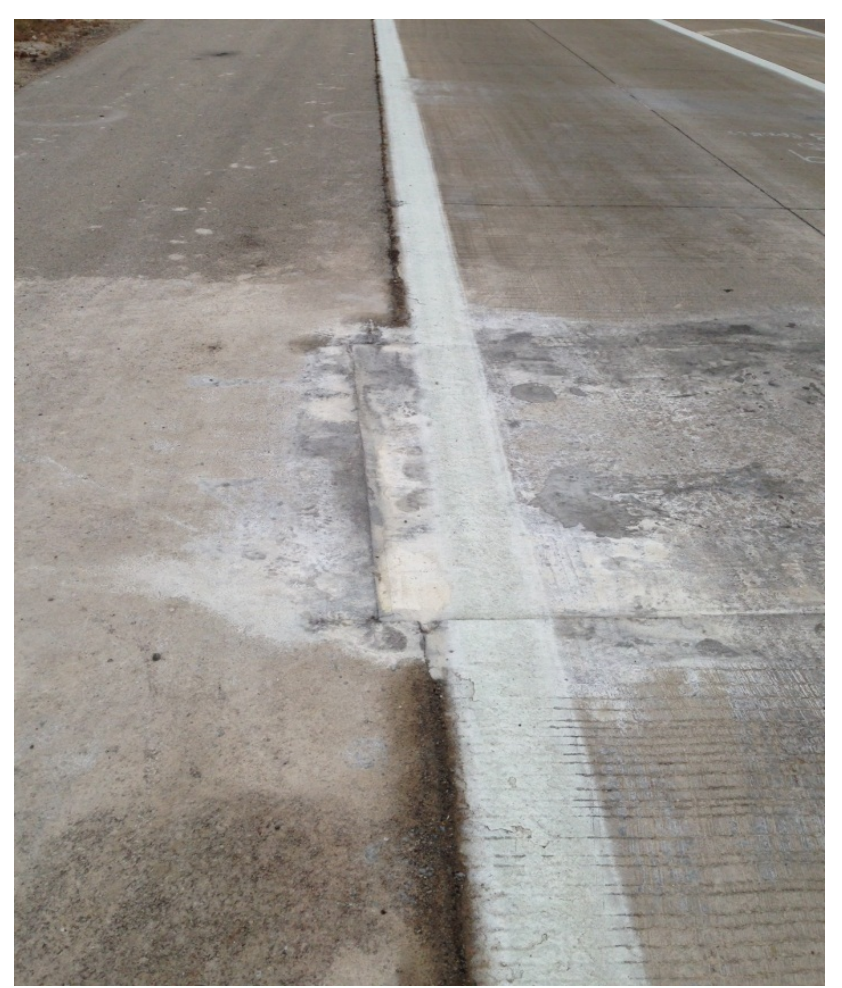




\section{Saw Cut Precisely and Remove Slurry}

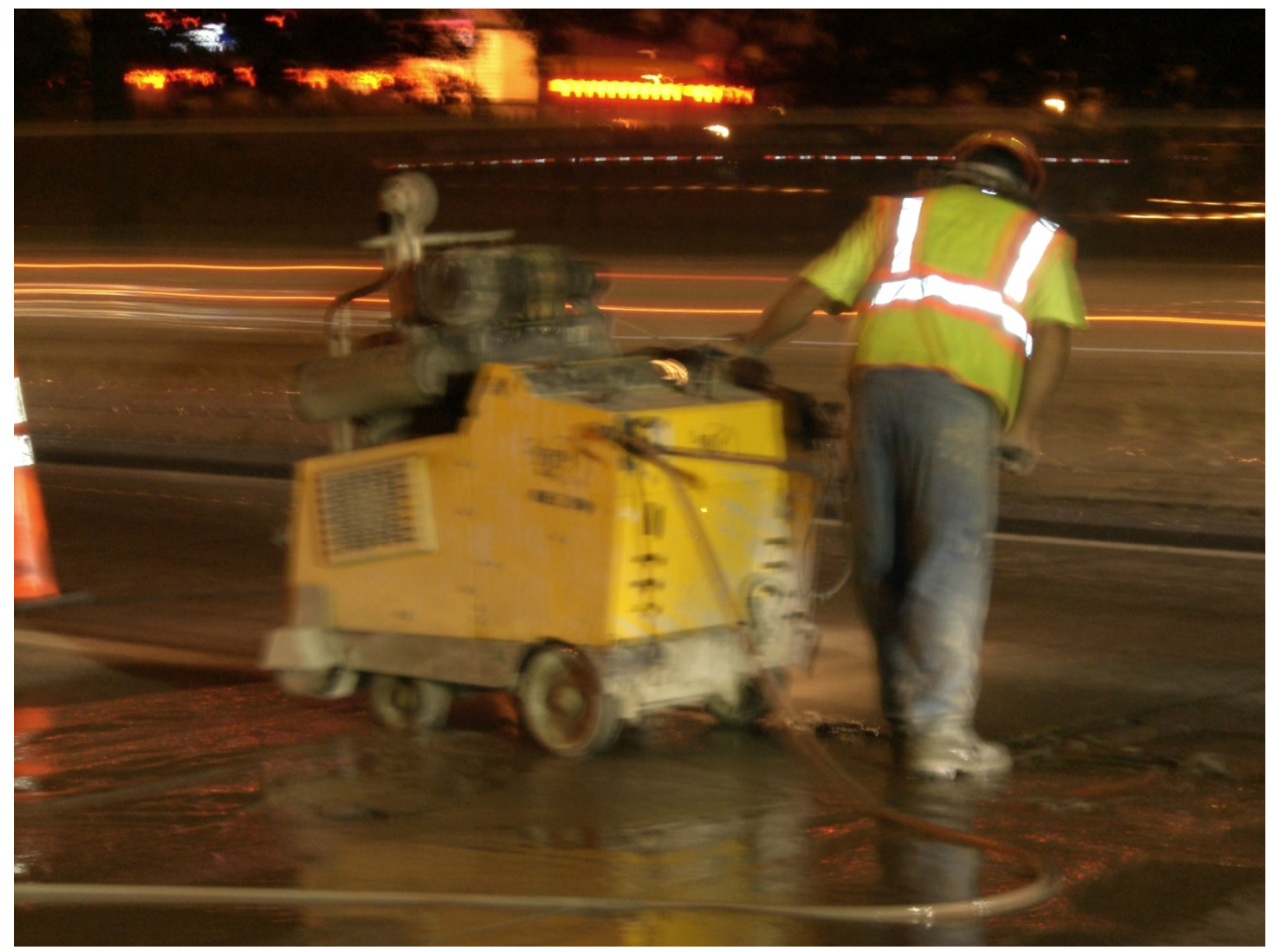




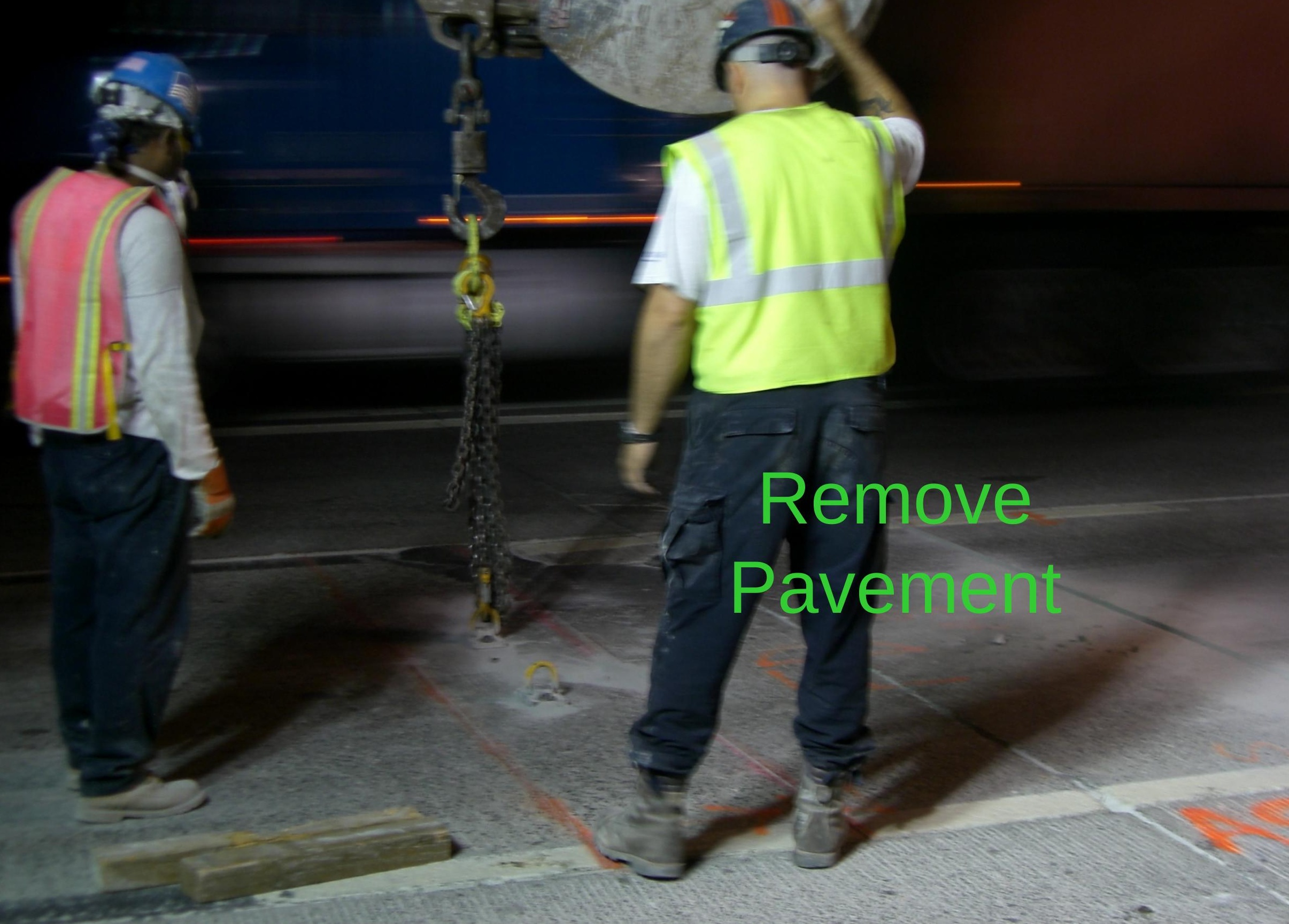




\section{Prepare and Compact Base}

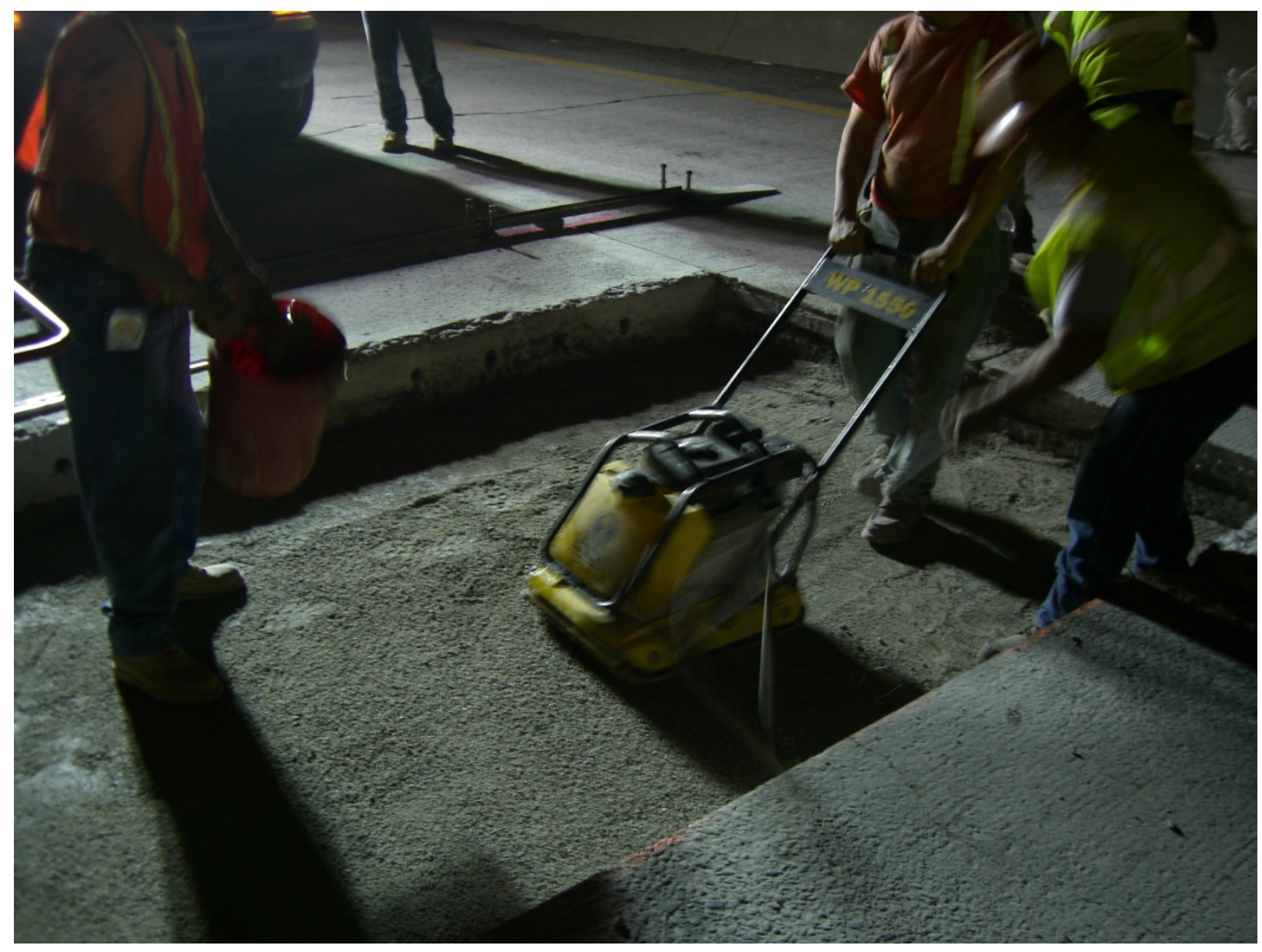




\section{Options For Leveling - Customized Flat Slabs}

$\square$ Flowable fill ( $\leq 1.5 \%$ cross slope) over restored subbase (no undergrout)

$\square$ Fine leveling sand over restored subbase (undergrout after retrofitting)

$\square$ Suspend slab over restored subbase in proper position (undergrout before retrofitting)

$\square$ High density poly urethane foam over restored subbase (no undergrout)

$\square$ Use leveling bolts followed by undergrout 


\section{Only Option for Leveling - Customized Slabs Placed at Non-Planar Locations}

$\square$ Cast the slabs flat with additional thickness

$\square$ Set slabs with at least one corner flush with adjacent surface and other corners above adjacent pavement

$\square$ Use previously listed options for leveling

$\square$ Profile diamond grind over thickened slabs to obtain desired elevations 


\section{Pre-mark Dowel Bar Drill Locations}

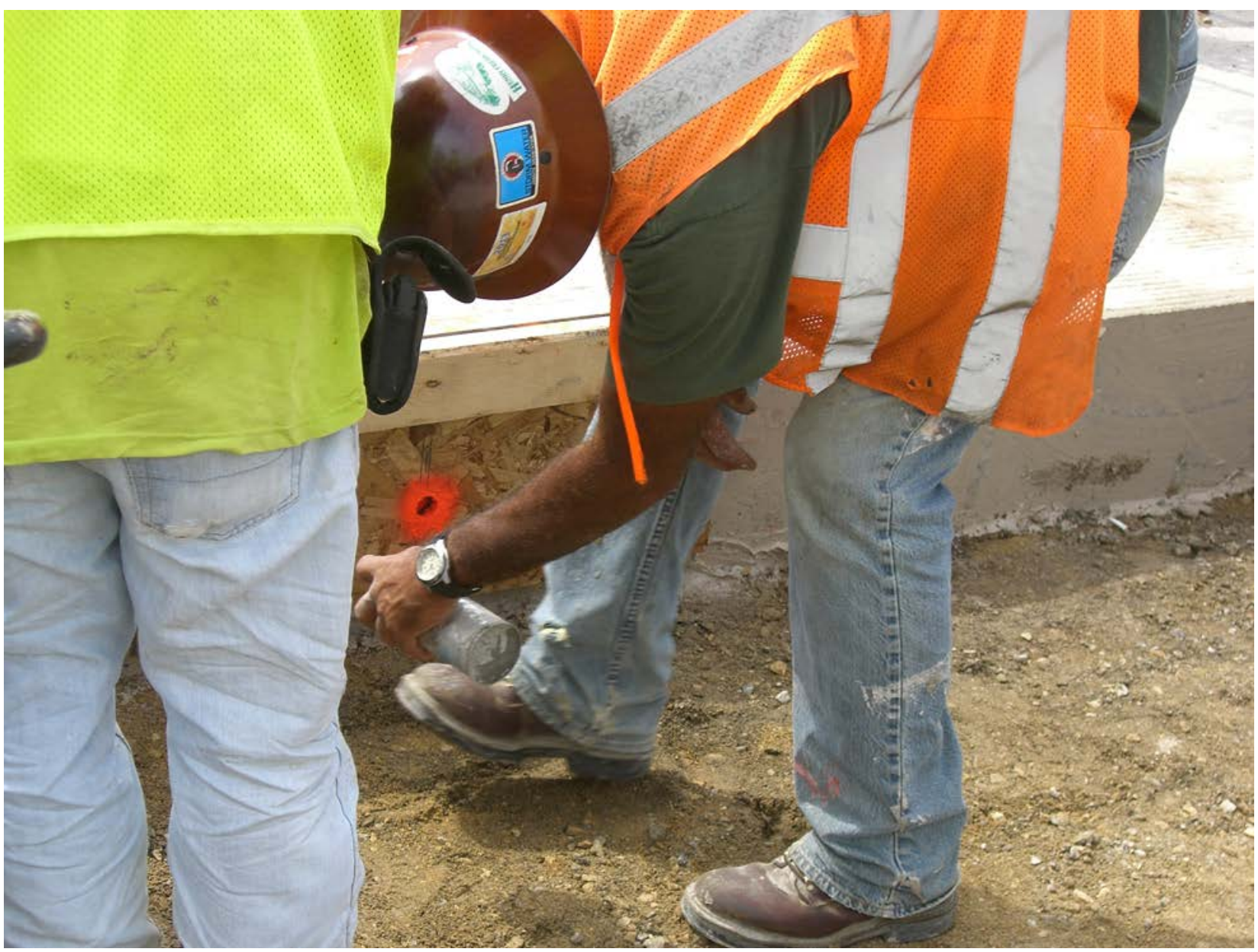




\section{Pre-drill Dowel Holes with Tollway System (Gang Drills Preferred)}
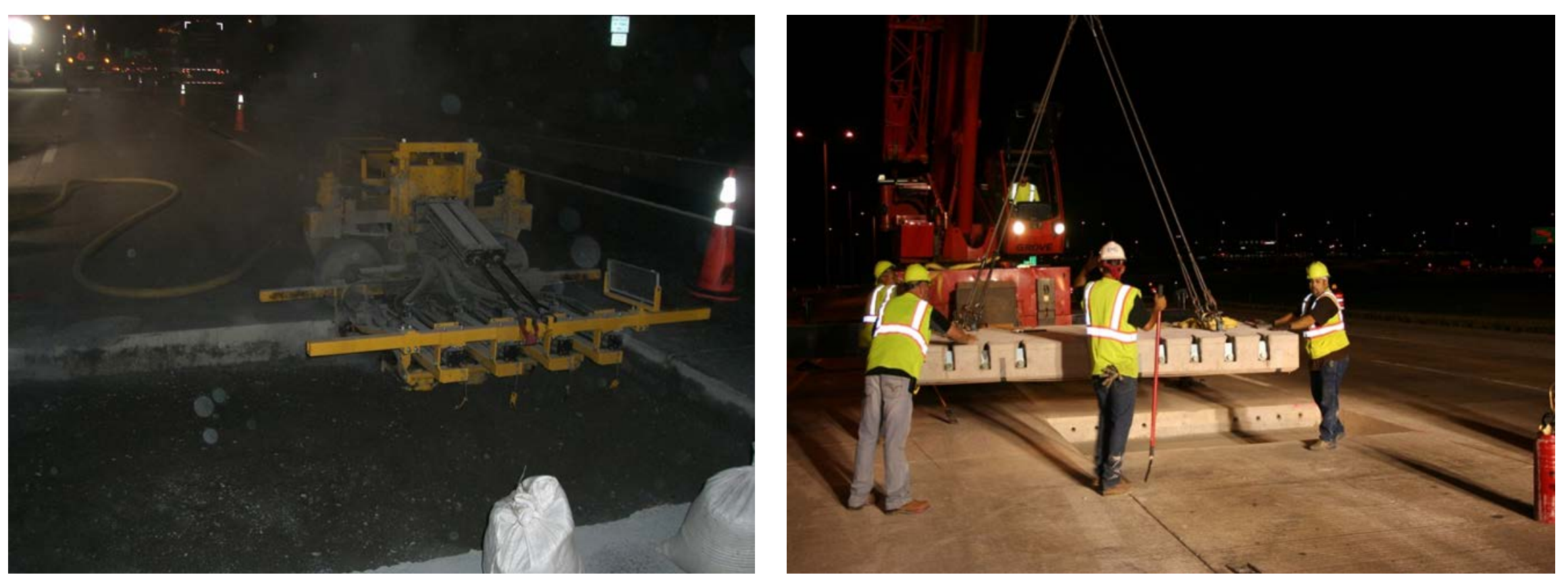


\section{Set Slabs}

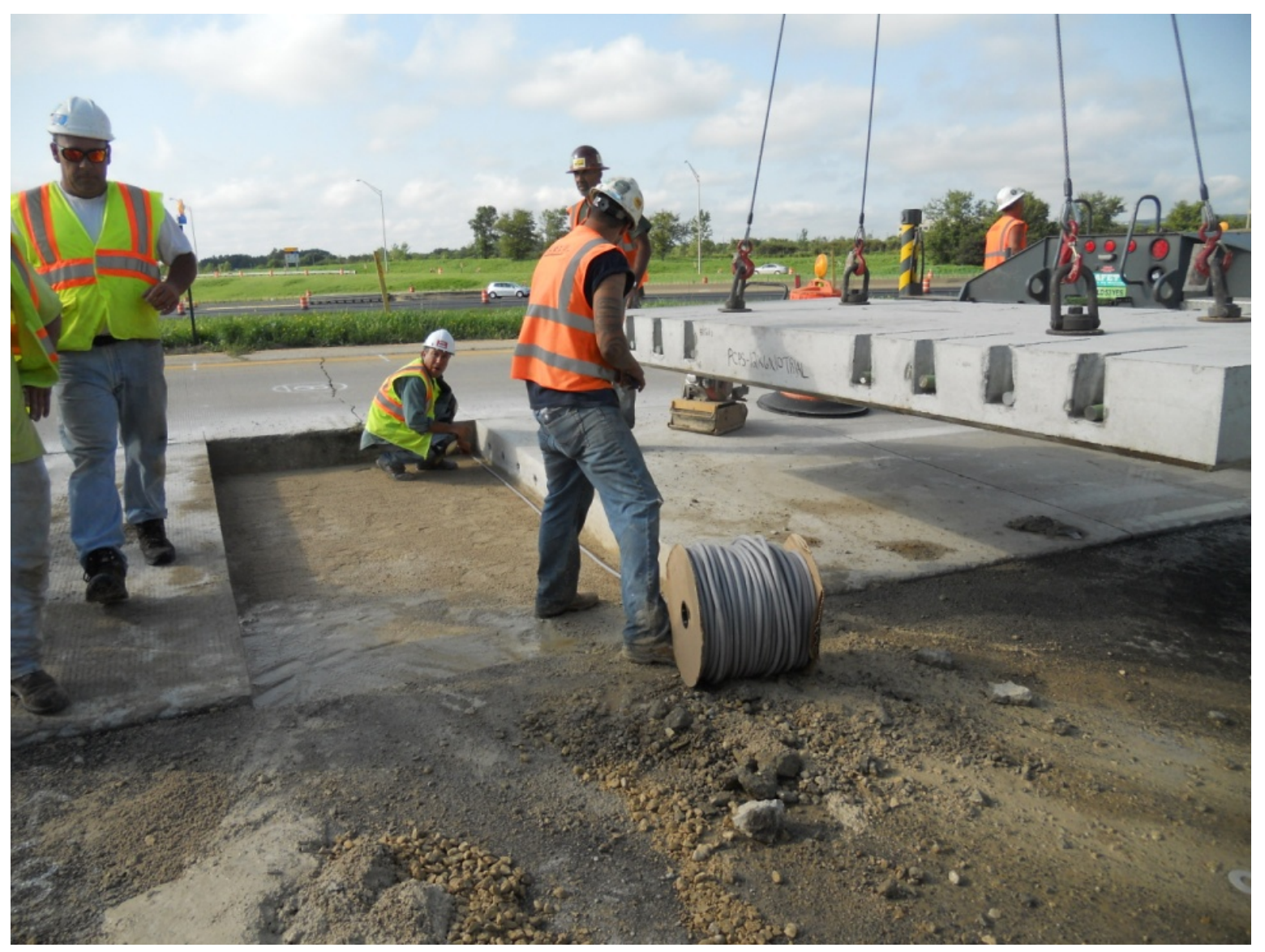




\section{Caulk the Joints with Tollway System}

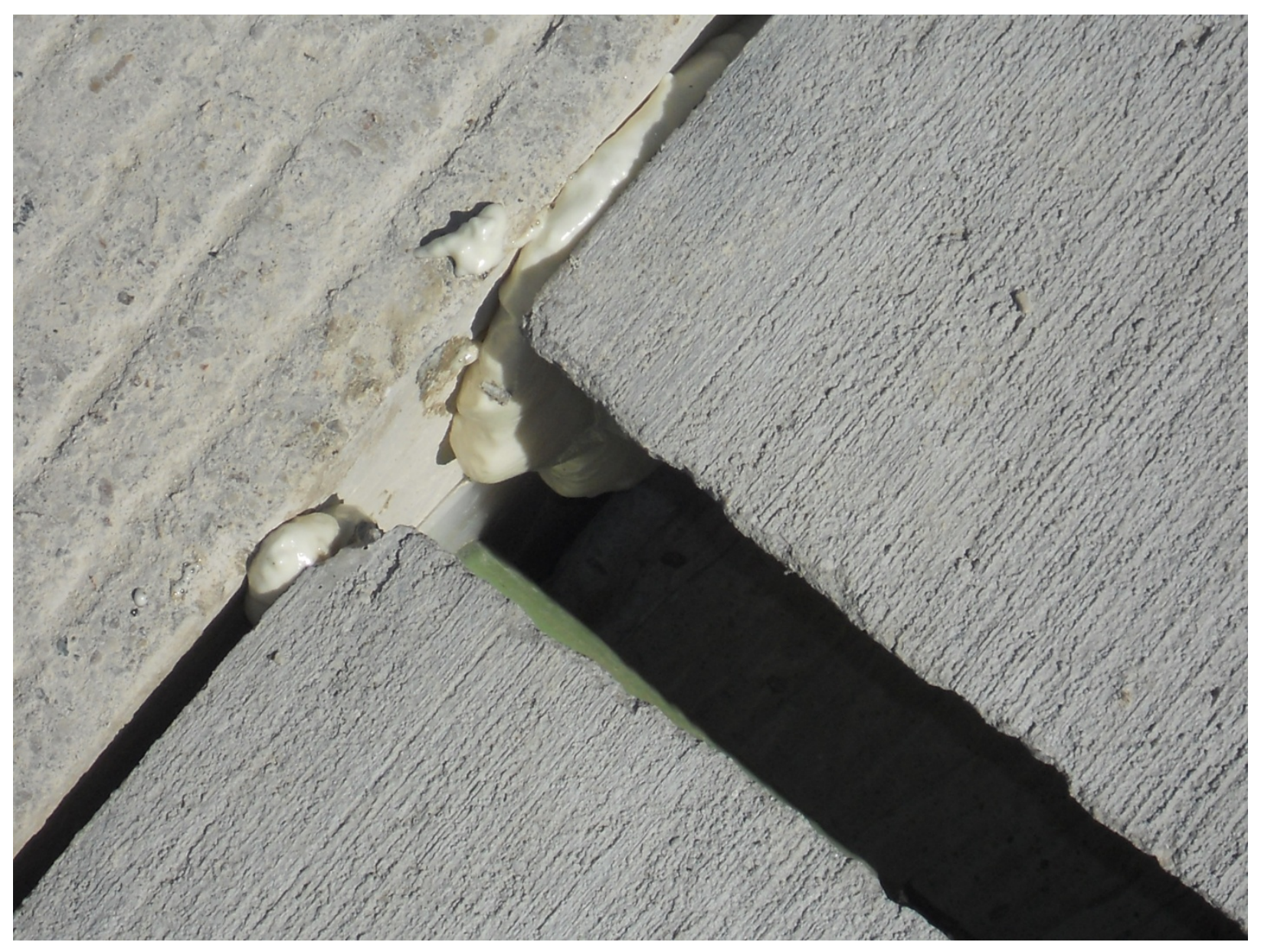




\section{Epoxy the Predrilled Holes With Narrow Slots Either $1^{\text {st }}$ or $2^{\text {nd }}$ Night}
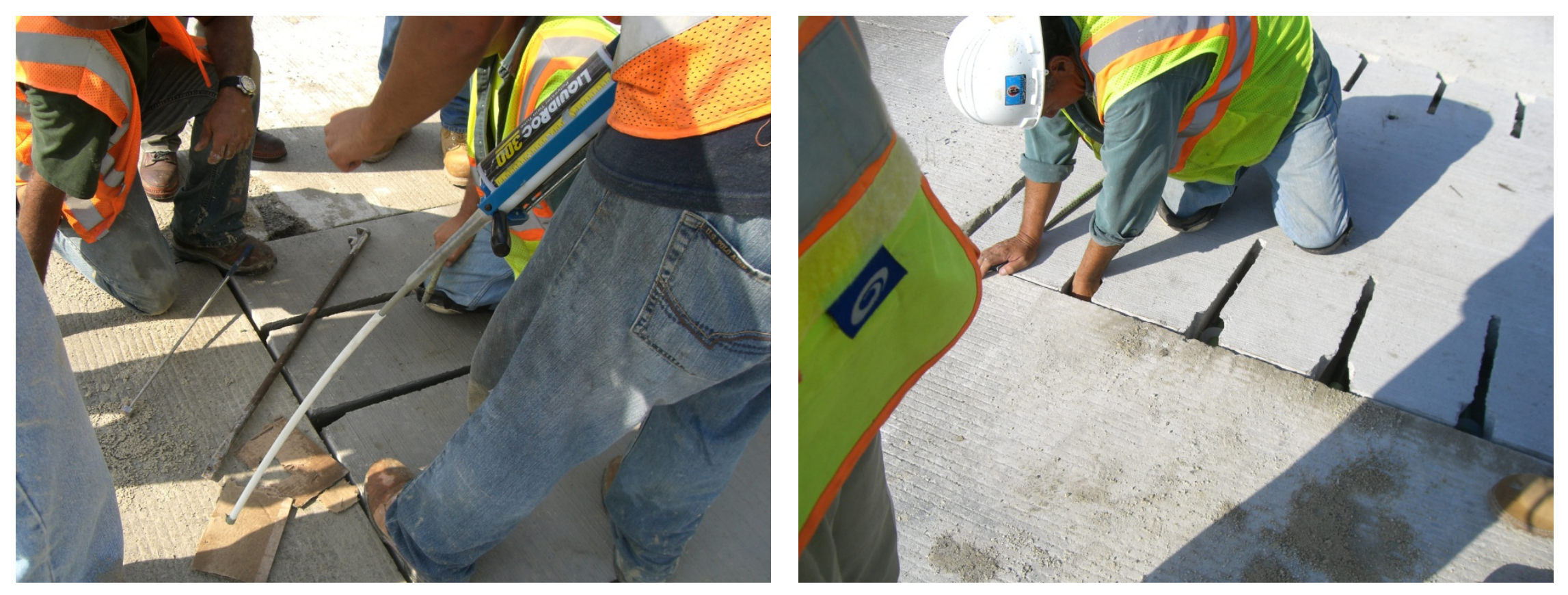


\section{Insert Dowel Bars}
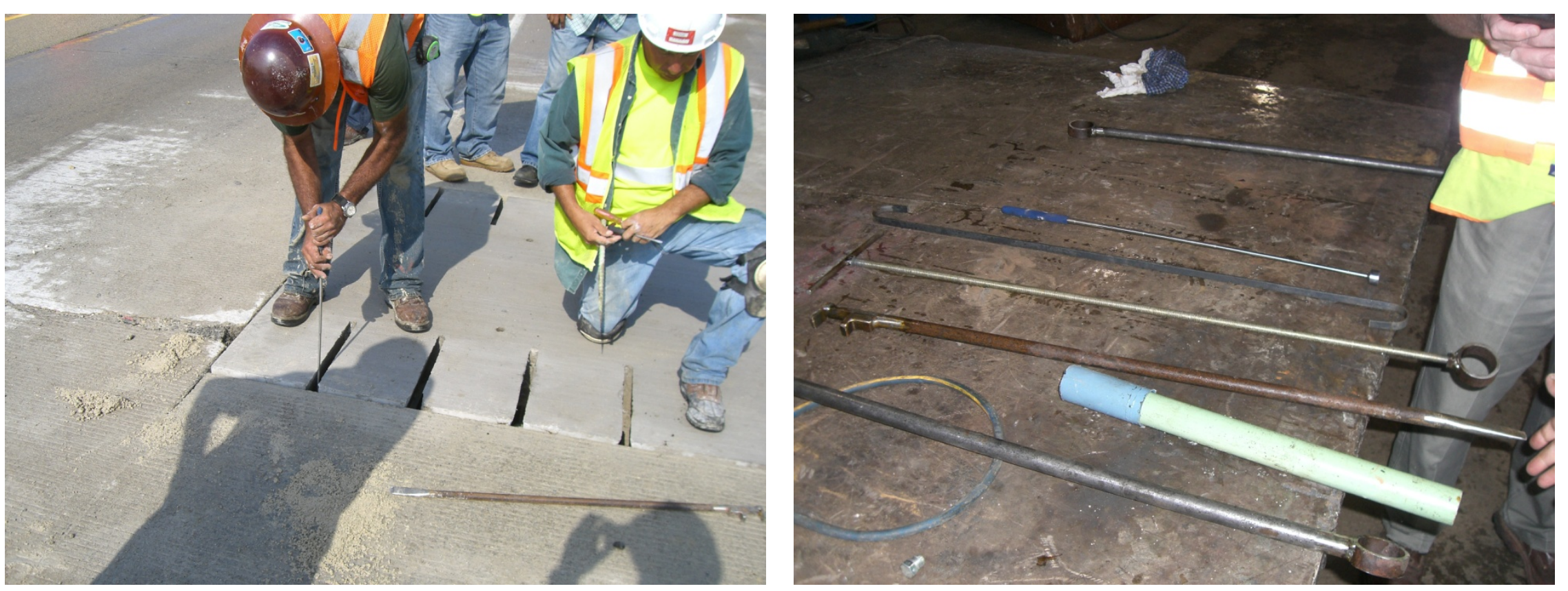


\section{Grout the Dowel Bar Slots with the Tollway System}

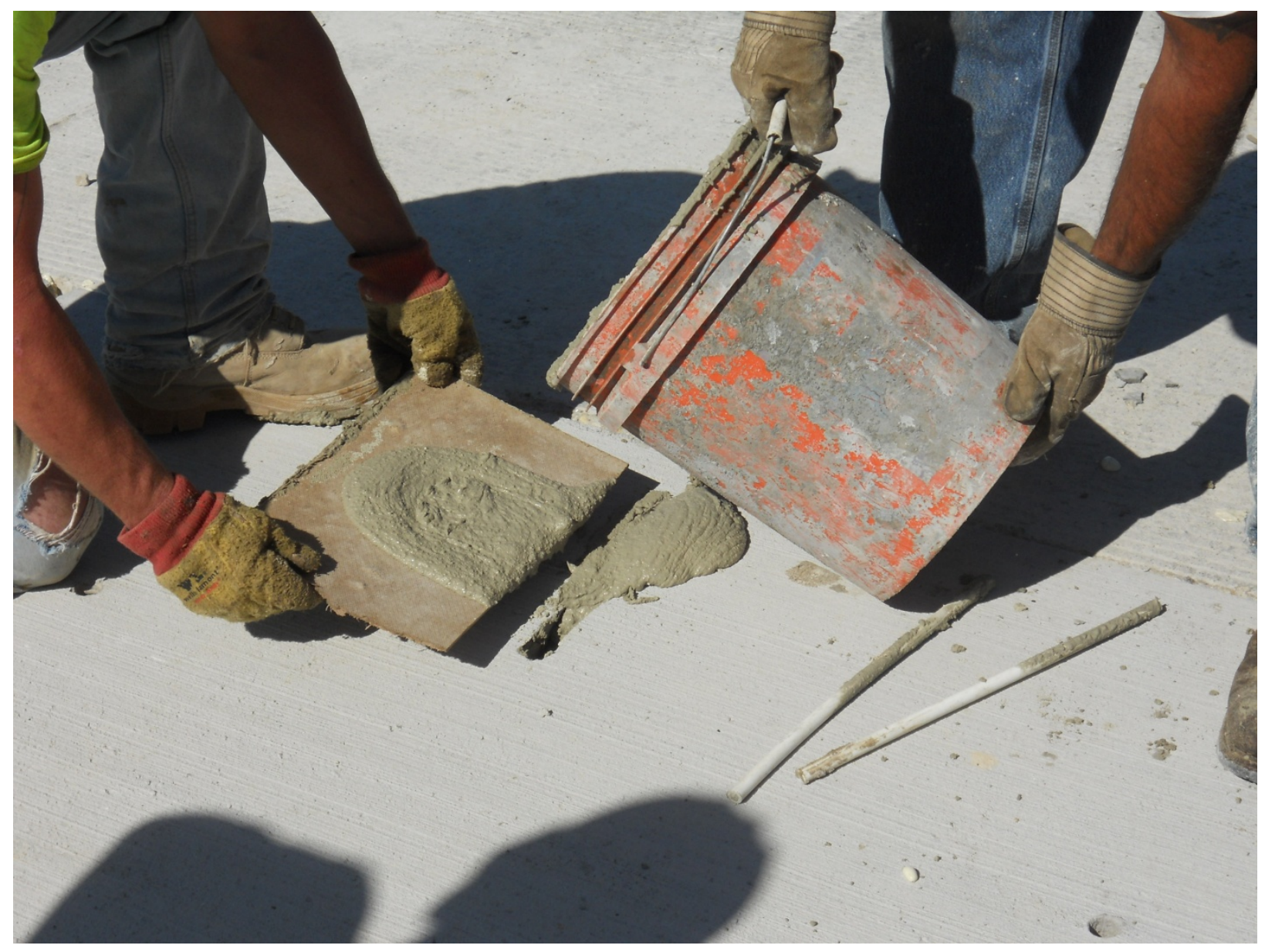




\section{Undergrout the Slabs Through Port Holes}

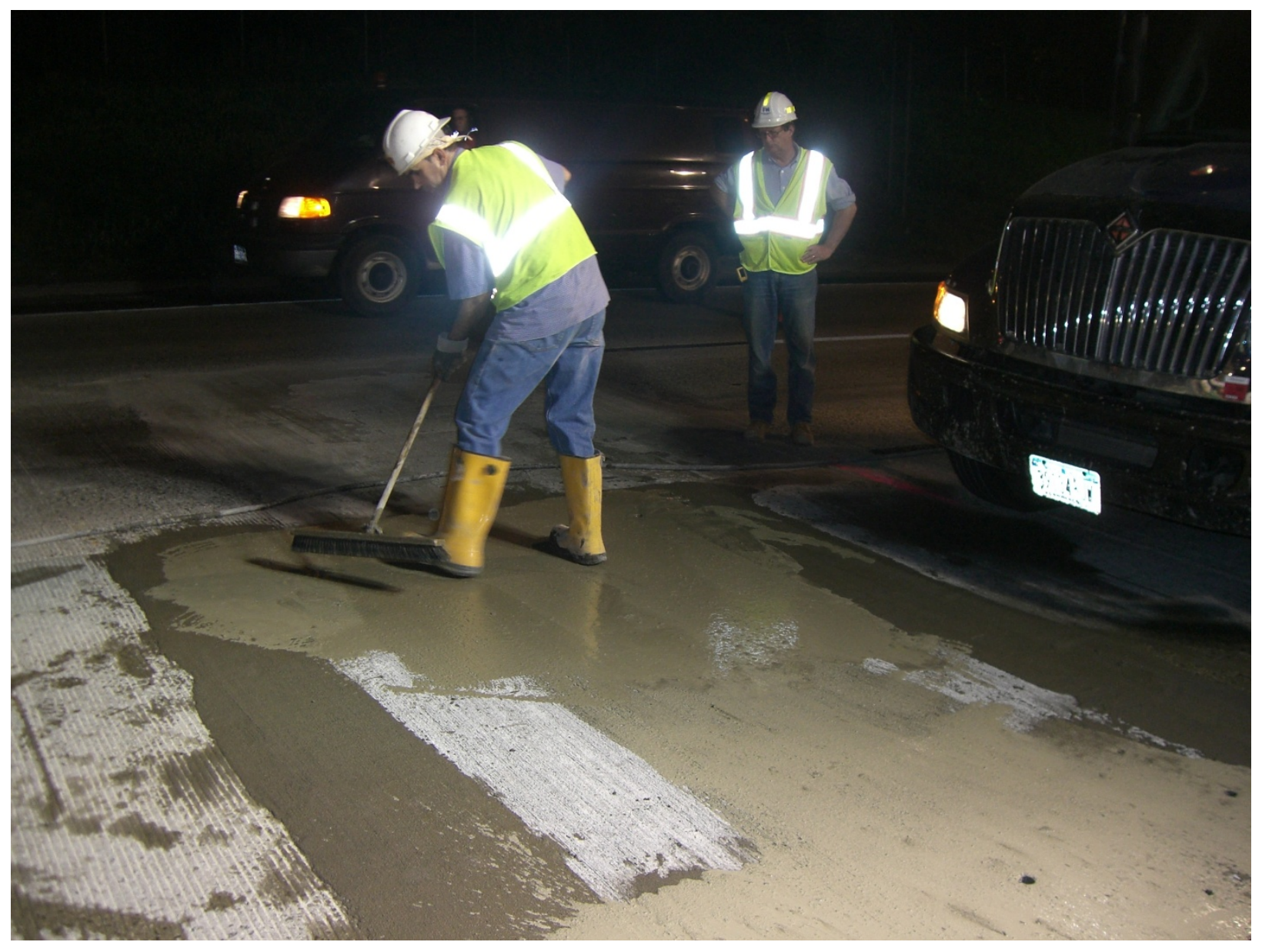




\section{Grind or Overlay the Finished Surface}

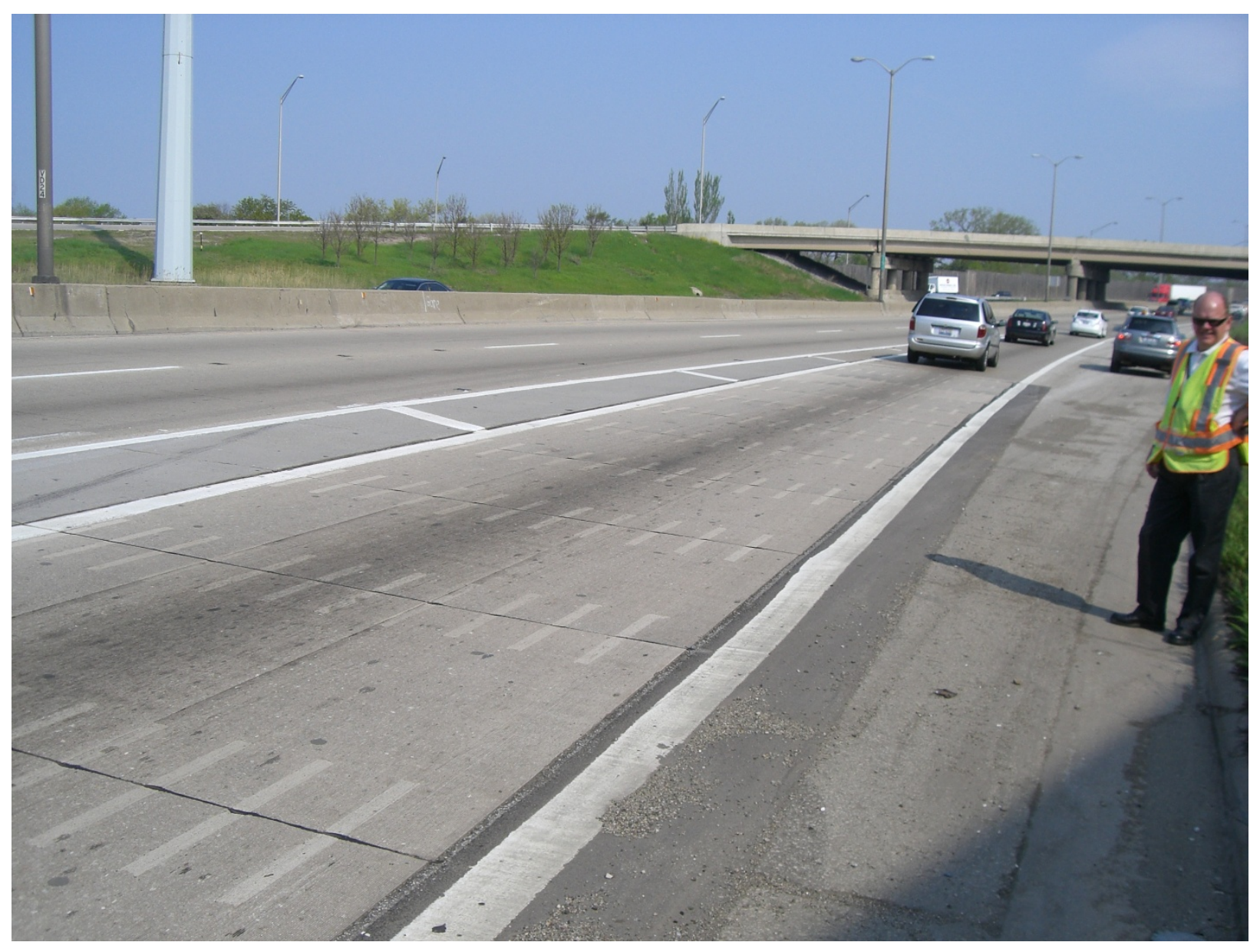




\section{Video of Tollway System Panel Placement for Isolated Joint/Slab Repairs of JPCP}




\section{Rules for Local Agency Applications}

$\square$ All slabs likely to be customized

$\square$ Forms are the responsibility of the fabricator

$\square$ Casting non-planar slabs can be a problem

$\square$ Any proposed system must be agency approved

$\square$ Upon completion of Contractor's survey, design, \& shop drawing approval fabrication and construction can start 


\title{
Applications
}

\author{
Isolated Joint / Slab Repairs
}
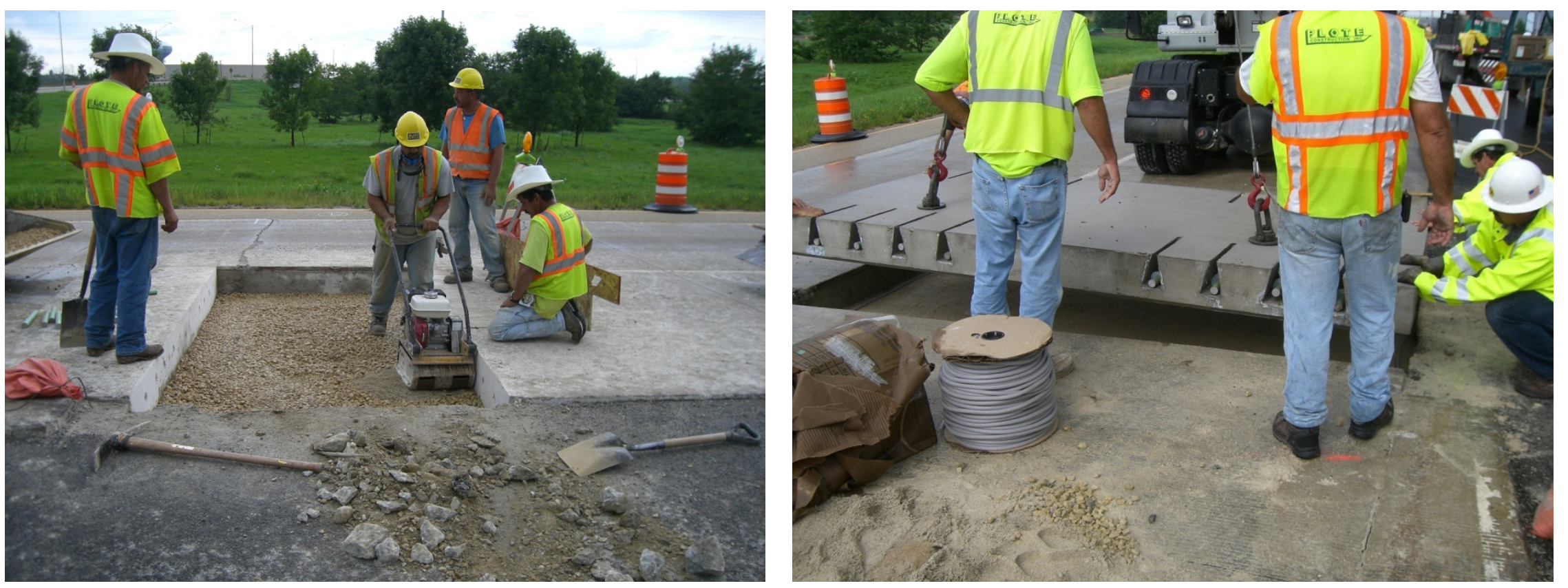


\section{Applications}

Large Area Repairs / Consecutive Slab Replacements
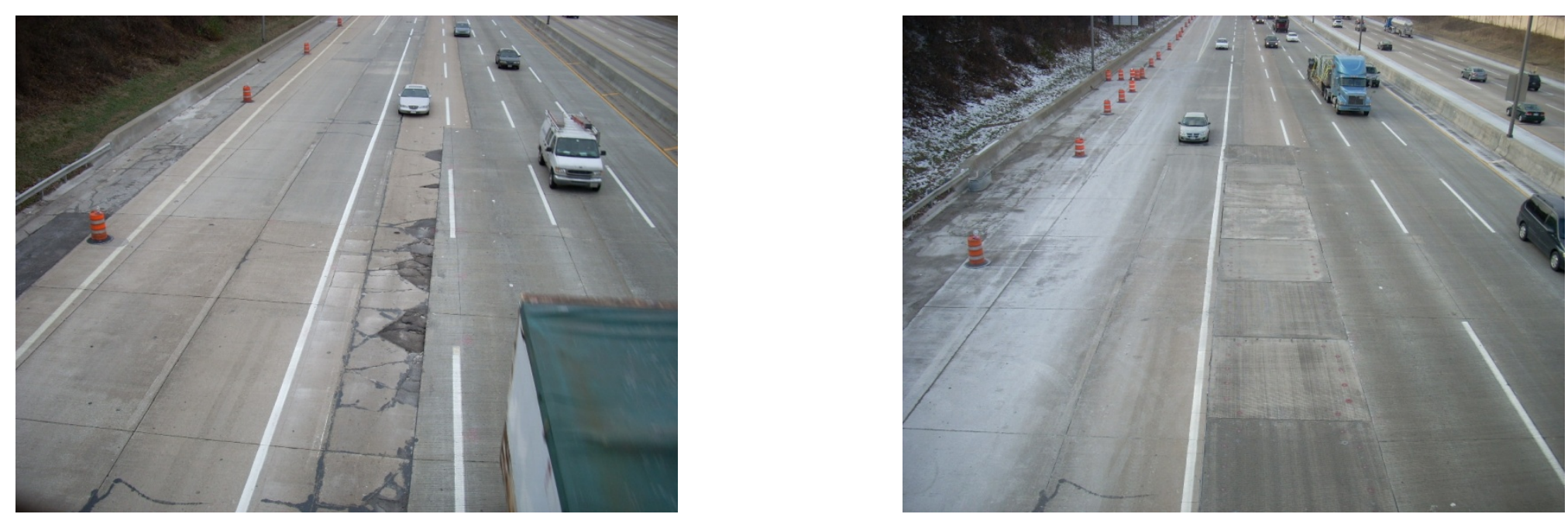


\section{Applications}

New Construction
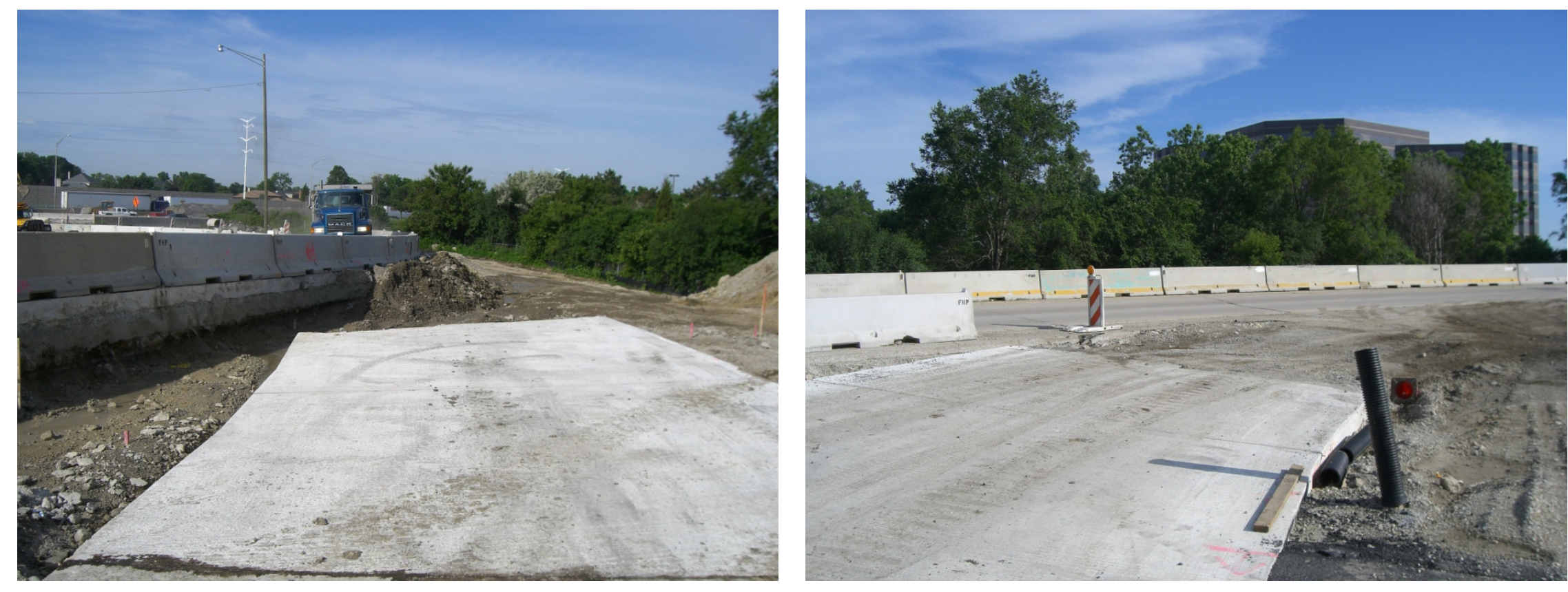


\section{Applications}

Ramp Reconstruction / Large Area Replacements
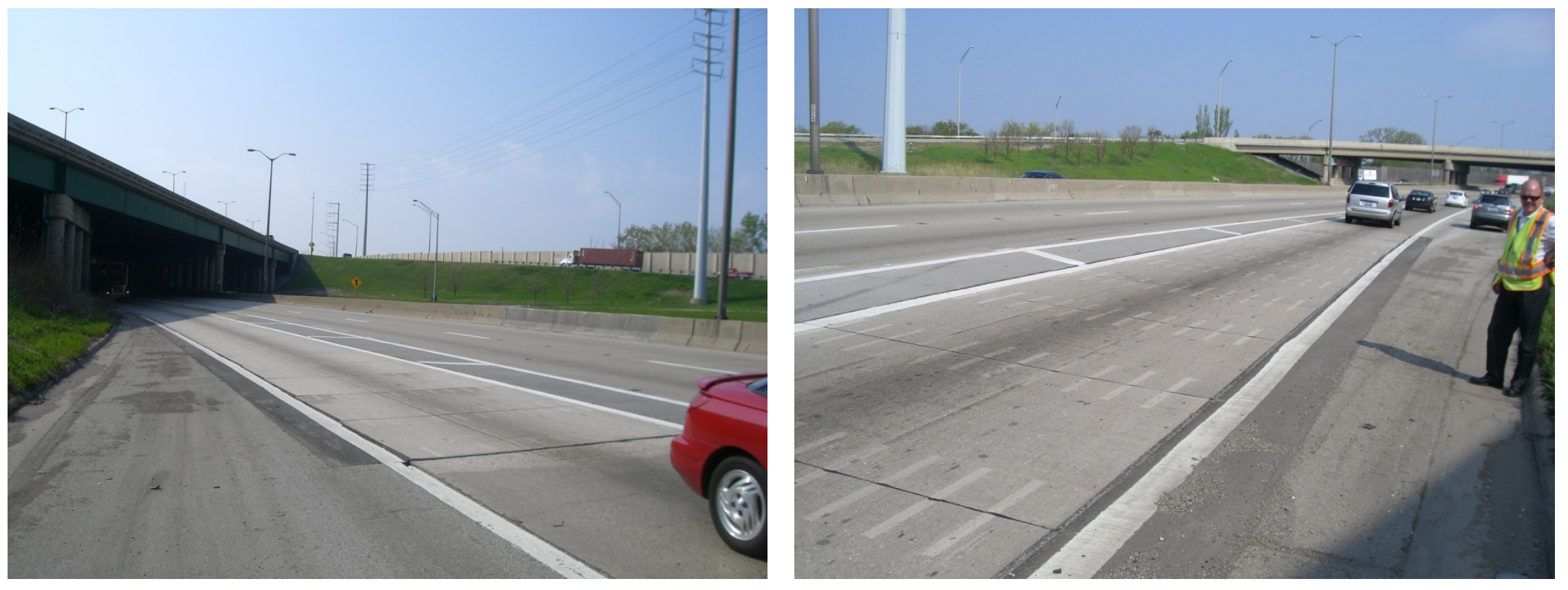


\section{Full Area Ramp Replacement Application}

Laser controlled grading

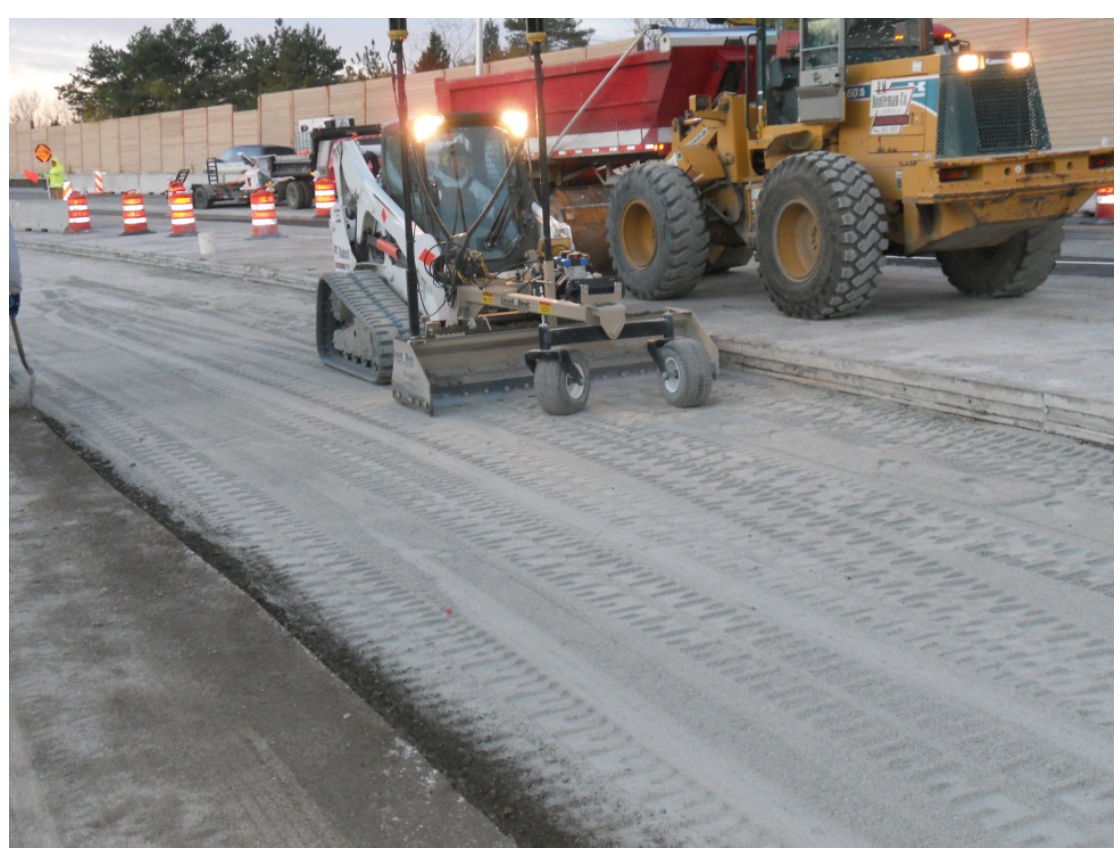

$\approx 100$ slabs set over 4 weekends

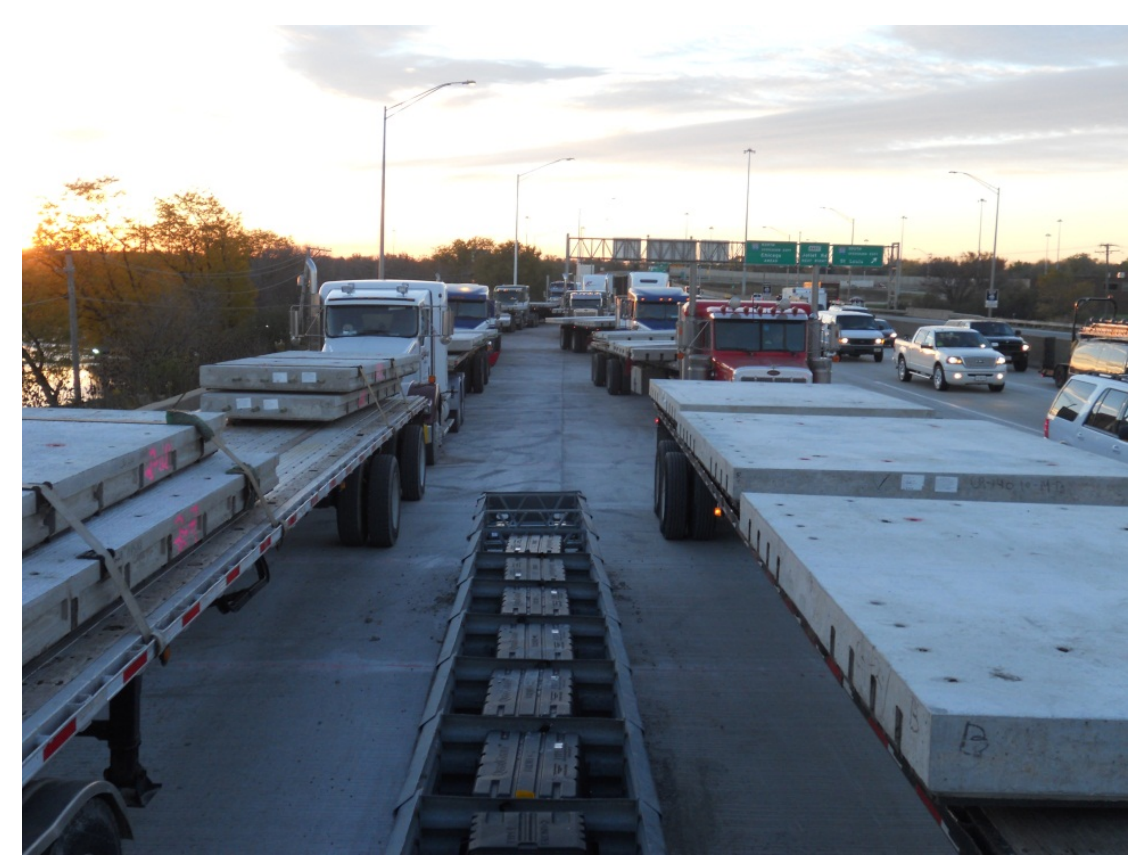




\section{Applications}

Intersection Reconstruction Overnight
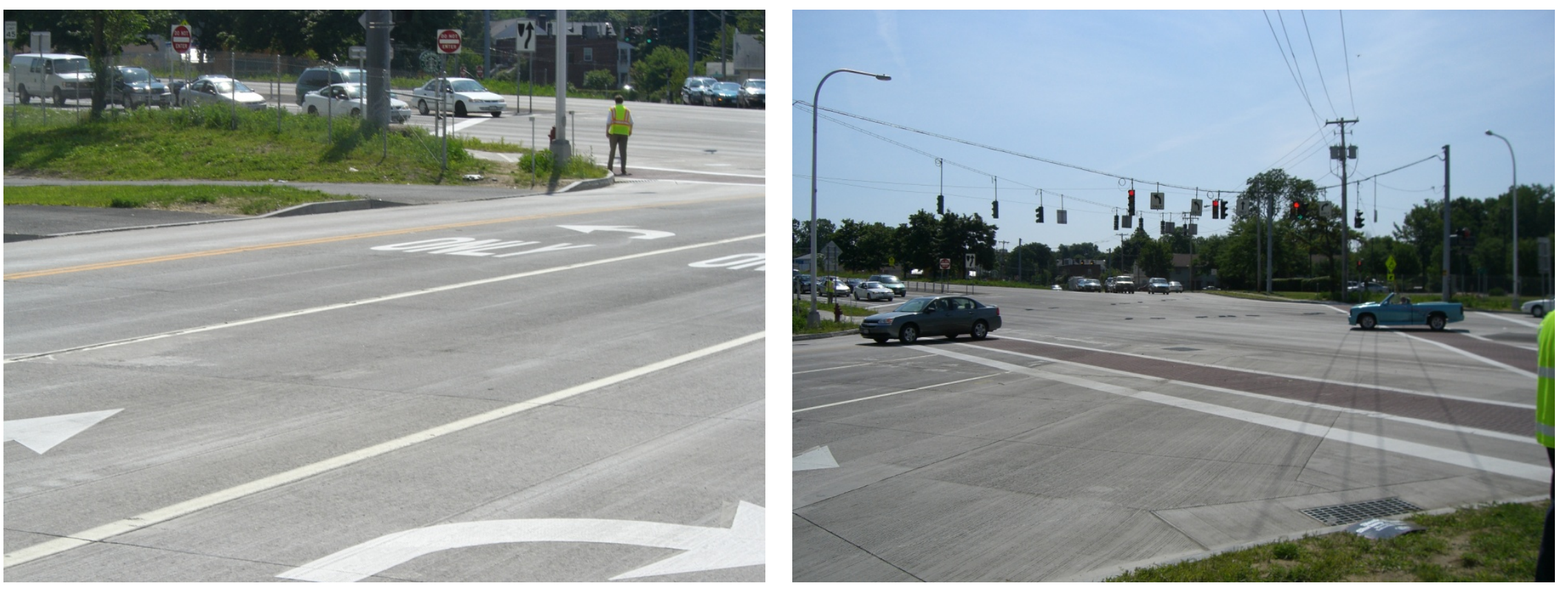


\section{Also, Precast Approach Slabs for:}

$\square$ Rehabilitating existing settled approach slabs, under traffic

$\square$ New construction of long span integral abutment bridges will require precast approaches

$\square$ Stress cracking develops quickly as a result of bridge movement when cast-in-place concrete is green

$\square$ Accelerated Bridge Construction (ABC) with modular designs that will require precast approaches 


\section{Approach Slab Rehab Construction Sequence - - Permanent Slab Placement}

Full removal

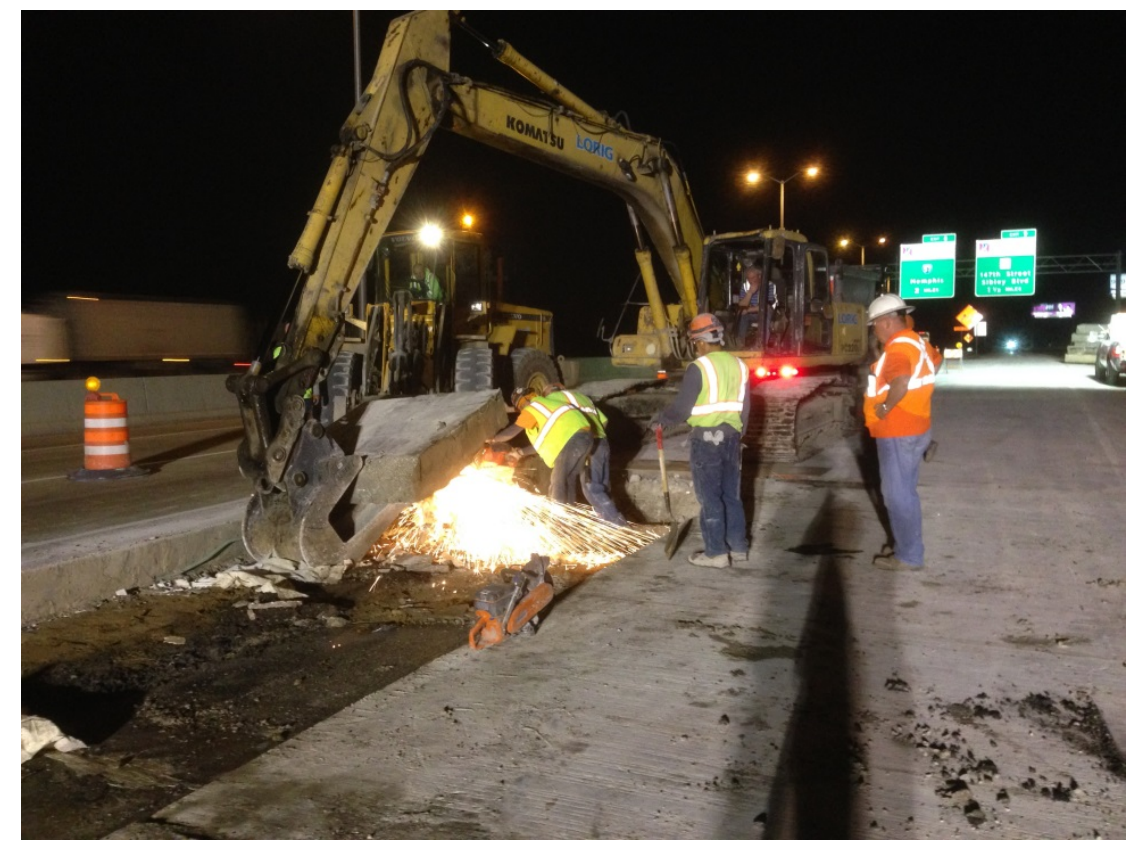

Set approach slab (30 ft. long)

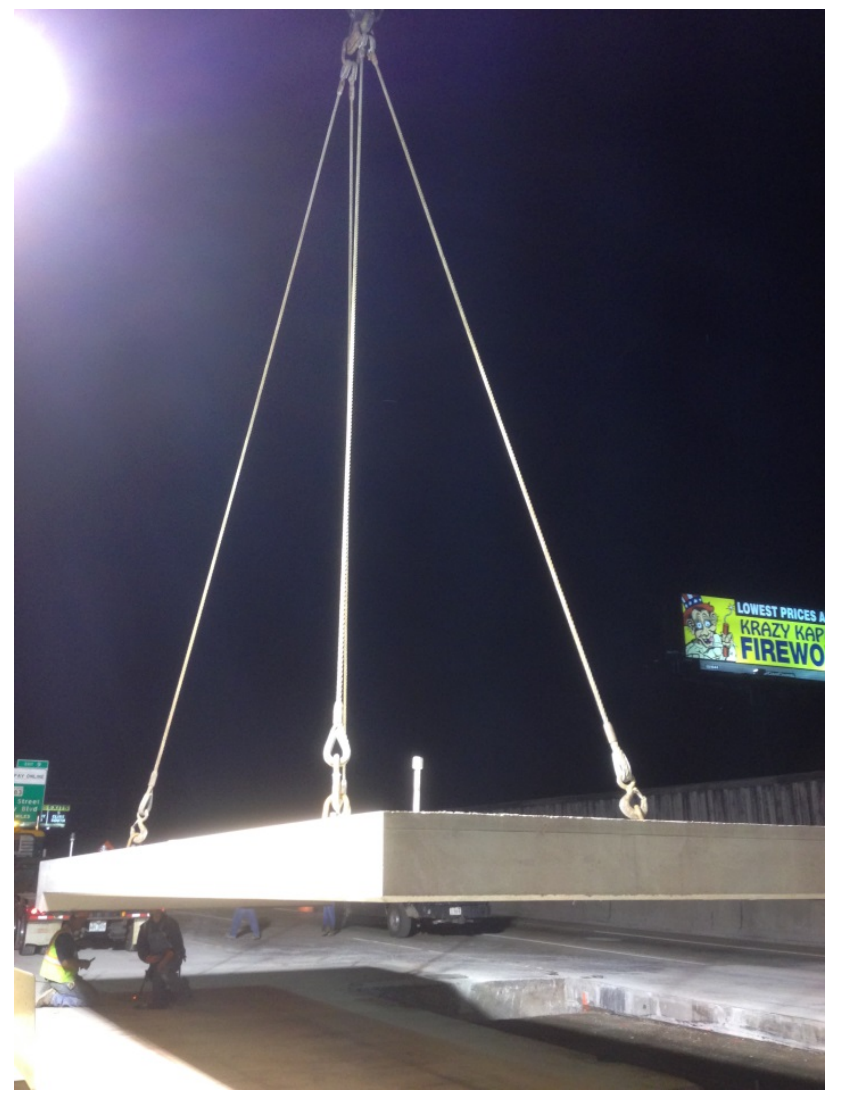




\section{Approach Slab Rehab Construction Sequence - - Level / Undergrout Slabs}

Adjust height w/ leveling bolts

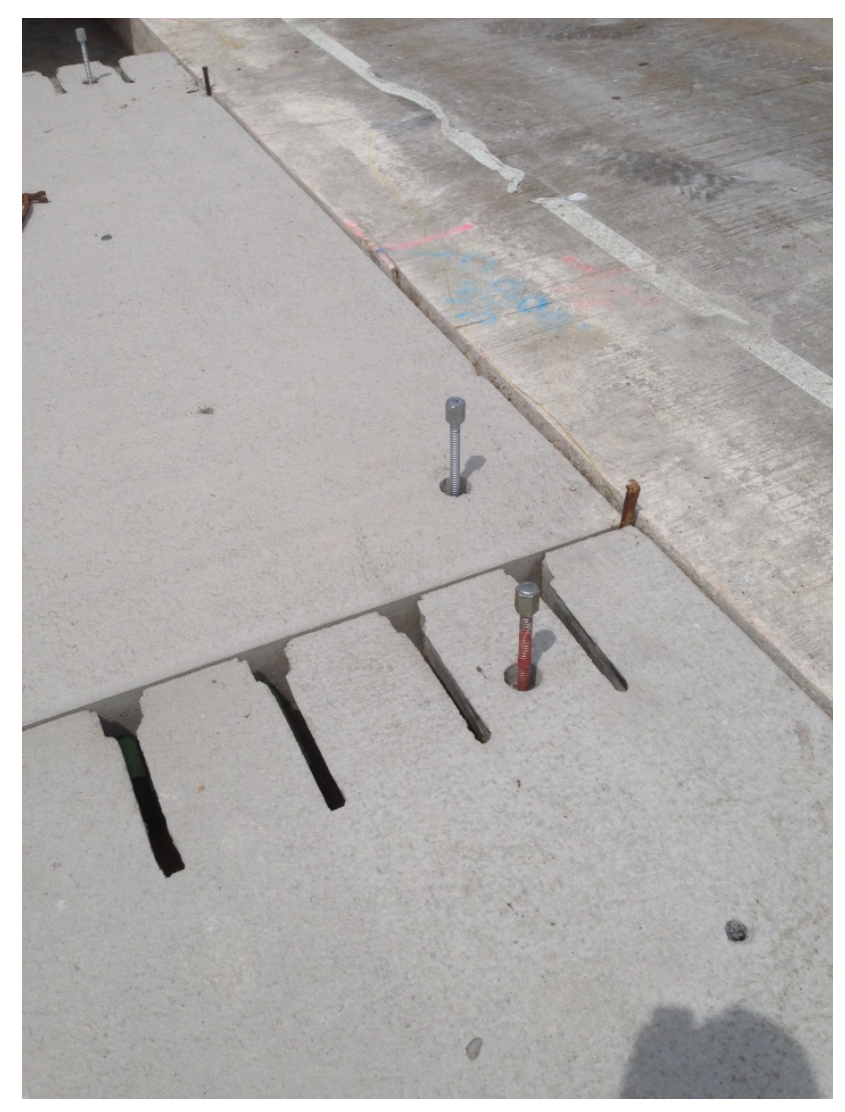

Undergrout slabs

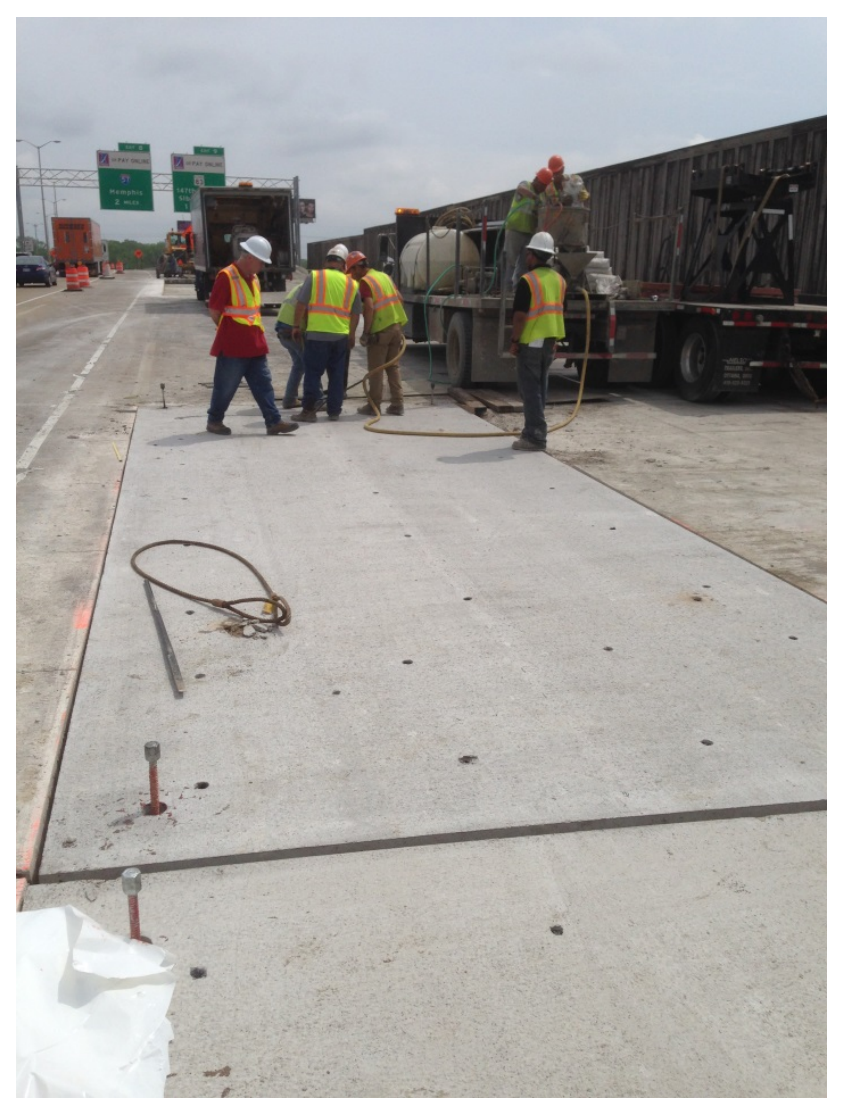


